\title{
Three tuf-like genes in the kirromycin producer Streptomyces ramocissimus
}

\author{
E. Vijgenboom, L. P. Woudt, † P. W. H. Heinstra, K. Rietveld, $\ddagger$ \\ J. van Haarlem, G. P. van Wezel, S. Shochat and L. Bosch
}

Author for correspondence: E. Vijgenboom. Tel: +3171274278 . Fax: +3171274340.

Department of Biochemistry, Leiden University, Gorlaeus Laboratories, PO Box 9502, 2300 RA Leiden, The Netherlands

\begin{abstract}
We have identified, cloned and sequenced three tuf-like genes from Streptomyces ramocissimus (Sr.), the producer of the antibiotic kirromycin which inhibits protein synthesis by binding the polypeptide chain elongation factor EF-Tu. The tuf-1 gene encodes a protein with $71 \%$ amino acid residues identical to the well characterized elongation factor Tu of Escherichia coli (Ec.EF-Tu). The genetic location of tuf-1 downstream of a fus homologue and the in vitro activity of Sr.EF-Tu1 show that tuf-1 encodes a genuine EF-Tu. The putative Sr.EF-Tu2 and Sr.EF-Tu3 proteins are $69 \%$ and $63 \%$ identical to Ec.EFTu. Homologues of tuf-1 and tuf-3 were detected in all five Streptomyces strains investigated, but tuf-2 was found in S. ramocissimus only. The three tuf genes were expressed in $E$. coli and used to produce polyclonal antibodies. Western blot analysis showed that Sr.EF-Tu1 was present at all times under kirromycin production conditions in submerged and surface-grown cultures of S. ramocissimus and in germinating spores. The expression of tuf-2 and tuf-3 was, however, below the detection level. Surprisingly, Sr.EF-Tu1 was kirromycin sensitive, which excludes the possibility that EF-Tu is involved in the kirromycin resistance of $S$. ramocissimus.
\end{abstract}

Keywords: Streptomyces ramocissimus, tuf genes, EF-Tu, kirromycin

\section{INTRODUCTION}

The polypeptide chain elongation factor EF-Tu of E. coli is one of the most abundant proteins in the bacterial cell and fulfils an essential function in protein synthesis. The factor is encoded by two so-called tuf genes (Jaskunas et al., 1975; Yokota et al., 1980; An \& Friesen, 1980), which are well separated on the chromosome and are located in completely different genetic contexts (Lindahl et al., 1977; Lee et al., 1981). The gene products differ in one single amino acid at the $\mathrm{C}$-terminus. The functional significance of this tuf gene 'duplication' is not well understood. The two genes in $E$. coli, tuf $A$ and tufB, are coordinately expressed in an 1:1 ratio throughout growth, indicating that the organism sets value on the presence of both genes (van der Meide et al., 1983a, b).

† Present address: Dept of Biotechnology, Zaadunie BV, PO Box 26, 1600 AA Enkhuizen, The Netherlands.

¥Present address: Gist-brocades BV, Wateringseweg 1, PO Box 1, 2600 MA Delft, The Netherlands.

The EMBL accession numbers for the sequences reported in this paper are X67057, X67058 and X67059 (tuf-1, tuf-2 and tuf-3, respectively).
The initial findings in E. coli led to studies of the $\operatorname{tuf}$ gene organization in various eubacteria (Sela et al., 1989; Filer \& Furano, 1981; Ludwig et al., 1990) and an archaeobacterium (Lechner \& Böck, 1987). Southern blot analysis revealed that the gene 'duplication' is widespread among Gram-negative bacteria (Filer \& Furano, 1981). By contrast, the two Gram-positive bacteria, Bacillus subtilis and Micrococcus luteus, studied by these authors have only one tuf gene. These and later experiments led to the proposal that the difference in tuf gene number is characteristic for these two groups of bacteria. Similar studies, performed more recently and covering representatives of various phyla within the eubacterial kingdom, showed that there are exceptions to the rule. The fastidious Gram-negative bacterium Chlamydia trachomatis contains only one tuf gene (Goldstein et al., 1989), as is also true for the extreme thermophilic bacterium Thermatoga maritima (Bachleitner et al., 1989). One may even argue that $E$. coli does not meet the rule, since it harbours the selB gene encoding an additional EF-Tu, albeit a highly specialized one of strongly deviating size (Forchhammer et al., 1989). Exceptions are also found in the group of Gram-positive eubacteria. Several strains of the 
genus Clostridium were shown to contain more than one tuf gene (Sela et al., 1989).

The antibiotic kirromycin inhibits protein synthesis by binding to EF-Tu which causes retention of the factor on the ribosome and immobilization of the latter on the mRNA (Wolf et al., 1977). Kirromycin belongs to the group of elfamycins, antibiotics with polyene structures (Edwards et al., 1992) which are produced by the Grampositive streptomycetes $S$. ramocissimus, $S$. collinus and a few others (Parmeggiani \& Swart, 1985; Cundliffe, 1989). Streptomycetes are representatives of the morphologically more complex genera of the Gram-positive bacteria. The life-cycle of the streptomycetes starts with germinated spores forming branched vegetative mycelia. From these mycelia aerial hyphae grow erect, the ends of which are converted into chains of spores. When mature, these spores are released in a dormant state, whereafter germination reinitiates the whole process (Chater, 1989). During the transition phase, leading to the appearance of aerial hyphae, streptomycetes produce secondary metabolites such as a wide variety of antibiotics.

Various mechanisms are exploited by antibiotic-producing organisms to protect themselves against their own product (Cundliffe, 1989). The mechanism used by kirromycin producers, like $S$. ramocissimus, is essentially unknown (Glöckner \& Wolf, 1984). Here we investigate the possibility that protection is achieved through the expression of a kirromycin-resistant EF-Tu species. Analysis of the tuf genes and their expression is a prerequisite. Much to our surprise we identified three rather divergent $t u f$-like genes, an unprecedented finding in prokaryotes. As a primary step towards identification of the products of the three tuf-like genes, they were heterologously expressed in E. coli using the lac promoter. With antibodies raised against two of the $t u f$ gene products we studied the temporal expression of the three tuf genes in $S$. ramocissimus. In both liquid cultures during kirromycin production and in surface-grown cultures when complete development takes place, only tuf- 1 is abundantly expressed but tuf- 2 and $t u f-3$ expression is below the detection level.

\section{METHODS}

Bacterial strains and plasmids. Cloning was done in E. coli strains 490, JM101 or JM109 (Messing, 1979; Yanisch-Perron et al., 1985), using the plasmid pUC8 (Vieira \& Messing, 1982) for tuf-1, and pAT153 (Twigg \& Sherratt, 1980) for $t u f-2$ and $t u f-3$. Subclones were made in pUC18 or pUC19 (Yanisch-Perron et al., 1985). In the heterologous expression studies strain KA797 [ara $\Delta($ lac pro $A B)$ thi $\mathrm{F}^{\prime}\left(\right.$ pro $A B^{+}$lac $\left.I^{Q}\right)$, collection of the Department of Molecular Genetics, Leiden University, The Netherlands] was sometimes used instead of JM101. S. ramocissimus was obtained from Gist-brocades NV, The Netherlands.

Cloning strategy. Both tuf- 1 and tuf- 2 were isolated by a combination of Southern hybridization and a sib-selection procedure. For cloning of tuf- 1 , chromosomal DNA of $S$. ramocissimus was digested with $B g / \mathrm{II}$ and ligated in Bam HIdigested pUC8. After transformation to E. coli, plasmid DNA was isolated from transformant pools, each pool representing about 300 colonies. This DNA was screened by Southern hybridization with a $H p a \mathrm{I}-N r u \mathrm{I}$ fragment of the $E$. coli tuf $A$ gene as probe. The positive pools were subsequently reduced in size until the clone harbouring tuf-1 (pUSRT1) was isolated. In order to identify the position of tuf- 1 on the Bg/II insert of pUSRT1, DNaseI deletion derivatives were generated essentially as described by Hong (1982). The location of tuf- 1 could be derived from the length of the insert, the $S a l l$ restriction pattern and Southern analysis which showed whether the SalI fragments that contain tuf sequences were still present. By this approach $t u f-1$ was localized in the middle of the $2.8 \mathrm{~kb} \mathrm{Bg} / \mathrm{II}$ fragment.

For cloning of $t u f-2$, BamHI-digested chromosomal DNA was fractionated on a $1 \%$ agarose gel and fragments with a length corresponding to the signal in a Southern blot probed with the tuf- 1 internal 330 bp and 240 bp SmaI fragments were ligated in pAT153. Clones were screened again by hybridization, using the sib-selection procedure. tuf-2 was mapped on the positive clone (pASRT2) by digestion with various enzymes, such as SalI, SmaI and PstI, and identification of the fragments carrying tuf-like sequences by Southern hybridization. The tuf- 2 gene was thus localized at one end of the $2.8 \mathrm{~kb} \mathrm{BamHI}$ fragment.

Cloning of tuf-3 was achieved in a one-step screening. The gene was localized on a $12 \mathrm{~kb} \mathrm{BamHI}$ fragment and a $9 \mathrm{~kb} \mathrm{BamHI}-$ EcoRI fragment by Southern hybridization using a $330 \mathrm{bp}$ internal fragment from the $t u f-1$ gene. Bam HI fragments with a length of $12 \mathrm{~kb}$ were isolated from an $1 \%$ agarose gel, digested with EcoRI and ligated in EcoRI- and BamHI-digested pAT153. Since EcoRI sites are very rare in Streptomyces DNA this approach should yield a high percentage of positive clones. DNA isolated from E. coli transformants was analysed directly by Southern hybridization. The tuf-3 gene was localized on the $9 \mathrm{~kb} \mathrm{BamHI-EcoRI} \mathrm{fragment} \mathrm{(pASRT3)} \mathrm{as} \mathrm{described} \mathrm{for} \mathrm{tuf-2.}$

Southern hybridization. Chromosomal DNA was isolated as described by Hopwood et al. (1988). DNA from $1 \%$ agarose gels was blotted to Hybond-N. Filters were hybridized with ${ }^{32} \mathrm{P}$ labelled probes in $6 \times \mathrm{SSC}, 0.1 \% \mathrm{SDS}, 1 \mathrm{mM}$ EDTA, $2 \times$ Denhardt's solution [0.04\% Ficoll $\left(M_{\mathrm{r}} 400000\right), 0.04 \%$ BSA, $0.04 \%$ polyvinyl pyrrolidone $\left.\left(M_{\mathrm{r}} 360000\right)\right], 0 \cdot 1 \%$ pyrophosphate, $200 \mu \mathrm{g}$ calf thymus DNA ml${ }^{-1}$ for $16 \mathrm{~h}$ at $65^{\circ} \mathrm{C}$. When $50 \%$ formamide was used in the hybridization buffer, the incubation was done at $42{ }^{\circ} \mathrm{C}$. Filters were washed in $6 \times \mathrm{SSC}$ at $65^{\circ} \mathrm{C}$ and $2 \times \mathrm{SSC}$ at $65^{\circ} \mathrm{C}$ for heterologous hybridizations and $0.5 \times \mathrm{SSC}$ or $0.2 \times \mathrm{SSC}$ at $65^{\circ} \mathrm{C}$ for homologous hybridizations.

Dephosphorylated DNA probes were labelled with [ $\left.{ }^{32} \mathrm{P}\right]$ ATP and T4 polynucleotide kinase, essentially as described by Maniatis et al. (1982), or labelled with the random prime method (Feinberg \& Vogelstein, 1983, 1984).

DNA sequencing. Sequencing was done by the dideoxynucleotide method of Sanger et al. (1977) and M13mp18 or mp19 as vector (Yanisch-Perron et al., 1985). 7-Deaza-2'-deoxyguanosine triphosphate was used to minimize band compression due to GC-rich regions

Growth of cultures. The E. coli strains were freshly transformed with the indicated plasmids and cultured in LB medium at $37^{\circ} \mathrm{C}$. Media were supplemented with $100 \mu \mathrm{g}$ ampicillin $\mathrm{ml}^{-1}$ and transcription from the lac promoter was induced by adding $0.5 \mathrm{mM}$ IPTG. Streptomyces strains were cultured at $30^{\circ} \mathrm{C}$ in baffled flasks in various liquid media: $\mathrm{S}$ medium $(4 \mathrm{~g}$ peptone, $4 \mathrm{~g}$ yeast extract, $10 \mathrm{~g}$ glucose, $0.5 \mathrm{~g} \mathrm{MgSO}_{4} .7 \mathrm{H}_{2} \mathrm{O}, 2 \mathrm{~g}$ $\mathrm{KH}_{2} \mathrm{PO}_{4}$ and $2 \mathrm{~g} \mathrm{~K}_{2} \mathrm{HPO}_{4}$ per litre of water), $\mathrm{TSB}+1 \%$ Casamino acids, YEME or YMG (for details on media see Hopwood et al., 1985). Solid media for surface-grown material 
were: R2YE and MM (Hopwood et al., 1985). For S. ramocissimus $200 \mathrm{ml}$ of minimal medium was supplemented with $2 \mathrm{ml}$ trace elements, $8 \mathrm{ml} 250 \mathrm{mM} \mathrm{CaCl}, 3 \mathrm{ml} 7.5 \mathrm{mg}$ methionine $\mathrm{ml}^{-1}, 3 \mathrm{ml} 7.5 \mathrm{mg}$ leucine $\mathrm{ml}^{-1}$ and $5 \mathrm{ml} 15 \mathrm{mg}$ tyrosine $\mathrm{ml}^{-1}$. Mannitol $(0 \cdot 5 \%)$ was used as carbon source. Strains were grown on cellophane discs to facilitate harvesting of the mycelium.

Protein extraction. Cells were harvested by centrifugation. Thereafter all procedures were carried out at $4{ }^{\circ} \mathrm{C}$. The cells were washed once in standard buffer $(10 \mathrm{mM}$ Tris $/ \mathrm{HCl} \mathrm{pH} 7 \cdot 8$, $60 \mathrm{mM} \mathrm{NH} \mathrm{NH}_{4} \mathrm{Cl}, 10 \mathrm{mM}$ magnesium acetate, $0.05 \% \quad \beta$ mercaptoethanol, $1 \mathrm{mM}$ PMSF). Cells were sonicated at $30 \mathrm{~W}$ on ice with 10 bursts of $45 \mathrm{~s}$, allowing $15 \mathrm{~s}$ in between for cooling. The sonicated suspension was centrifuged at $30000 \mathrm{~g}$ for $30 \mathrm{~min}$, yielding the $\mathrm{S} 30$ (supernatant) fraction. In some cases an additional centrifugation was performed at $100000 \mathrm{~g}$ for $2 \mathrm{~h}$ yielding the $\mathrm{S} 100$ (supernatant) fraction.

Isolation and purification of elongation factors. Electrophoretically homogeneous EF-Tu.GDP from E. coli and EFTu1.GDP from $S$. ramocissimus were isolated by affinity chromatography of S100 supernatant fractions over GDP-AHSepharose as described by Jacobson \& Rosenbusch (1977) and by van der Meide et al. (1980). This procedure includes dialysis overnight of a mixture of the elongation factor and GDP-AHSepharose against buffer lacking GDP. The factor, bound to the $\mathrm{AH}$-Sepharose, is eluted with a GDP-containing buffer.

The product of $t u f-1$, heterologously expressed in E. coli, was purified in two steps. First the S30 extract was put on a column of GDP-AH-Sepharose, which retains the E. coli EF-Tu but lets EF-Tu1 pass through (note that no overnight dialysis occurs). Subsequently, the solution containing EF-Tu1 was transferred to a column of Red A or Blue B Matrix gel (Amicon), which was eluted with a $0-1 \mathrm{M} \mathrm{NaCl}$ gradient, EF-Tu1 appearing around $450 \mathrm{mM} \mathrm{NaCl}$. For the isolation of the tuf-3 product from E. coli see Results.

Freeze-sweeping. Proteins of the cell extracts were submitted to $2 \%$ agarose gel electrophoresis in $100 \mathrm{mM}$ Tris/borate buffer, $\mathrm{pH}$ 8.5. Part of the gel was stained with Coomassie Brilliant Blue to visualize proteins. The $t u f-3$ gene product was cut from the unstained gel and transferred to small tubes, containing siliconized glasswool, and with a hole in the bottom. The tubes were kept at $-90^{\circ} \mathrm{C}$ for $60 \mathrm{~min}$, whereafter the protein was isolated by centrifugation $(2000 \mathrm{~g}, 15 \mathrm{~min}$, at room temperature).

Preparation of antibodies. New Zealand White rabbits were immunized with $10-100 \mu \mathrm{g}$ purified tuf- 1 or tuf-3 gene product and bled as described previously (Heinstra et al., 1986). Sr.EF-Tu1 from S. ramocissimus and Sr.EF-Tu1 and Sr.EF-Tu3 purified from recombinant $E$. coli were used.

SDSPAGE and immunoblotting. After SDS-PAGE on a $10 \%$ polyacrylamide gel according to Laemmli (1970) proteins were blotted to $0.45 \mu \mathrm{m}$ pore-size nitrocellulose sheets by an electrophoretic transfer for $1 \mathrm{~h}$ at $150 \mathrm{~mA}$ and $4{ }^{\circ} \mathrm{C}$. The blots were washed twice in TBST $(150 \mathrm{mM} \mathrm{NaCl}, 100 \mathrm{mM}$ Tris, $0.5 \%$ Tween-20, $\mathrm{pH} 8.0$ ) and treated with $1 \%$ ovalbumin in TBST for $1 \mathrm{~h}$ at room temperature. The blots were then incubated overnight at $4{ }^{\circ} \mathrm{C}$ in TBST with $0.5 \%(\mathrm{v} / \mathrm{v})$ human serum and with a $1: 2000$ diluted antibody preparation. Human serum was replaced by $5 \%(\mathrm{w} / \mathrm{v})$ non-fat milk if non-specific background signals had to be reduced. After rinsing in TBST, the blots were incubated for $30 \mathrm{~min}$ at room temperature with 2000 -fold diluted alkaline-phosphatase-conjugated goat antirabbit IgG in TBST. Blots were finally developed by staining with bromo-4chloro-3-indolyl phosphate and nitro blue tetrazolium.

\section{RESULTS}

\section{Isolation of three tuf-like genes from S. ramocissimus}

A Southern blot of $S$, ramocissimus chromosomal DNA digested with either BamHI, BglII or PstI revealed three bands ranging from $2 \cdot 8$ to $15 \mathrm{~kb}$ when hybridized with a E. coli tuf $A$ probe (Fig. 1). Two bands can be explained by a restriction site within a tuf gene with an expected size of about $1200 \mathrm{bp}$ but three bands cannot. Apparently, at least two separate $t u f$-like genes are present on the $S$. ramocissimus genome. Fragments were therefore cloned and sequenced for further identification.

Using a fragment completely internal to the E. coli tuf $A$ coding sequence ( $H p a \mathrm{I}-\mathrm{NruI}$ ) as a probe and E. coli as the host for cloning, a high background from the chromosomal genes was to be expected when screening libraries by colony hybridization. Therefore we applied a sibselection procedure in which Southern hybridization was used to screen plasmid DNA isolated from transformant pools. By successively reducing the pool size the $2.8 \mathrm{~kb}$ $B g / I$ fragment, which hybridizes strongly with the $t u f A$ probe (cf. Fig. 1), was cloned. The DNA sequence was determined and analysed by computer with the Wisconsin

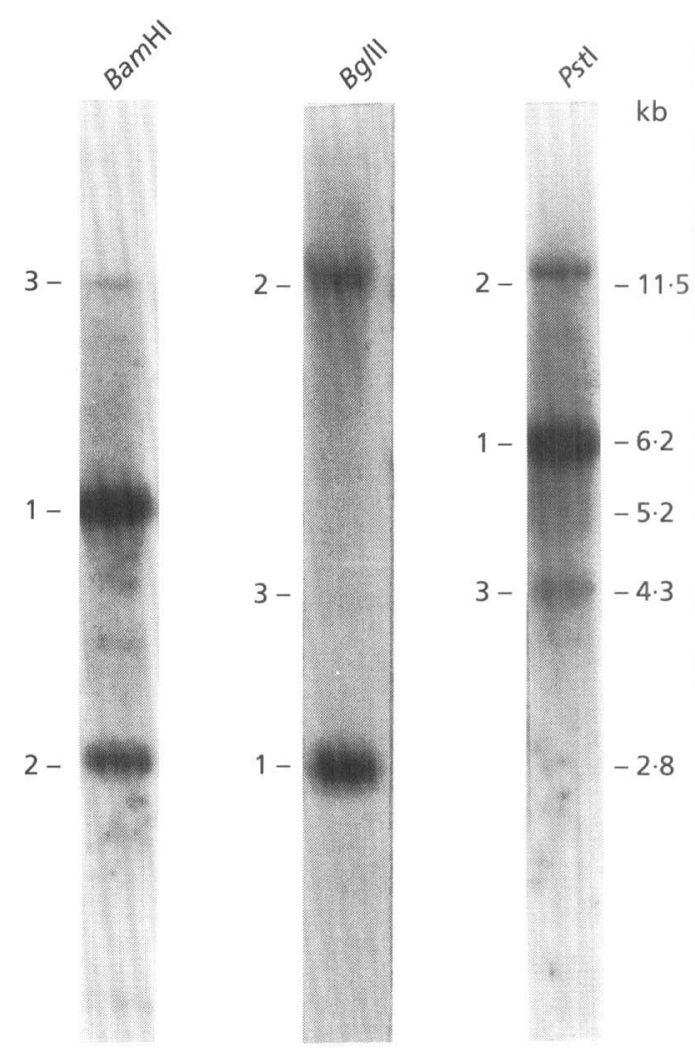

Fig. 1. Southern blot of S. ramocissimus chromosomal DNA. DNA was digested with BamHI, Bg/II or PstI and probed with the Hpal-Nrul fragment of E. coli tufA. The tuf gene identified on each of the signals is indicated with the corresponding number. The signal for tuf- 3 is not visible in the Bg/II lane but its position was identified on a Southern blot probed with the tuf-1 gene of $S$. ramocissimus (data not shown). 
(a) tuf-1

1 ATCTACCGCATG CACGCCAACAAGCGTYACGAGATTGAGTCGGTGGCCGCCGGTGACATEGTCGCCGTCA TGGGCC'TGAAGCAGACCACCACCGGTGAGA.

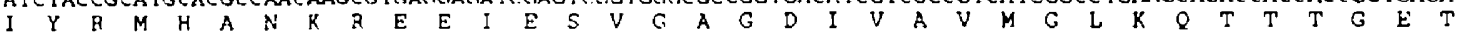

101 CGCTGTCCGACGAGAAGAGCCCGGTGATCCTGGAGTCCATGGACTTTCCGGCCCCGGTCATCCAGGTCGCCA TKGAGCCCAAGTCGAACGGCGACCAGGA

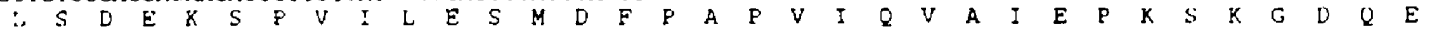

201 GAACCTCGGCGTCGCGATCCACCGCCTGGCCGAGGAGACCCCTCC TCCAGGTCCACTCCGACGAGGACACCGGCCAGACCATCATCGGCGGATGGGC

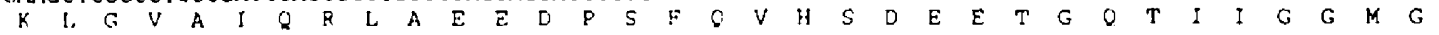

301 GAGCTGCACCTCGAGGTGCTGGTCOACCGTATGCGCCGTAGTTCANGGTCGAGGCCAACGTCGGCAGCCGCAGGTCGCGTACCGCGAGACGATCCGTC

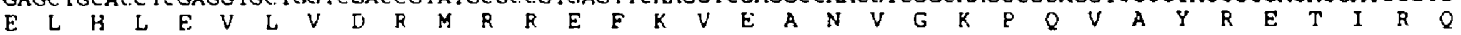

401 AGGCCGTCGAGAAGGTCGAGTACACCCACAAGAAGCAGACGGGTGGCACCGGCCAGTTCGCTCGCGTCATCATCGCGATCGAGCCCATCGAGAGCGGCGA $\begin{array}{llllllllllllllllllllllllllllllllll}A & V & E & K & V & E & Y & T & H & K & K & Q & T & G & G & T & G & Q & F & A & R & V & I & \text { I } & A & \text { I } & E & \text { P } & I & E & S & G & D\end{array}$

501 CACGTCGTACGAGTTCGTCAACAAGGTCACCGGTGGCCGCGTGCCGAGGAGTACATCCCCTCGGTCGACGCCGGTGCGCAGGAGGCCATGCAGTTCGGC

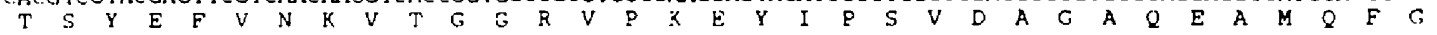

601 ATCC TCGCCGGTTACGAGATGACCGGTGTCCGCGTGACGCTGCTCG.ACGGCGCC TACCACGAGGTCGAC'TCCTCCGAGCTCGCGTTCAAGATCGCCGGTT

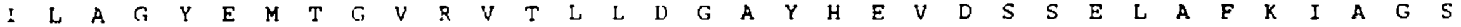

701 CGCAGGCCTTCAAGGAGGCCGCGCGGAAGGCCAAGCCCGTGCTCTTCAGCCGATGATGGCCGTCGAGGTCACCACGCCCGAGGACTACATGGGTGAGGT Q A F K F F A A R K A K

80: CATCGGCGACATCAACTCCCGCCGTGGCCAGATCCAGGCCATGGAG GAGCGGGCCGGTGCCCGCGTCGTGAAGGGTCTCGTGCCCCTCTCGGAGATGTIC

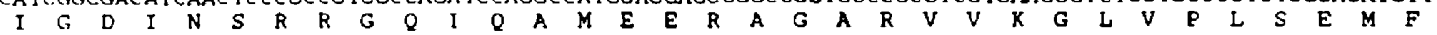

901 GGTTACGTCGGCGACCTGCGCAGCAAGACGTCCGGCCGGCCAGCTACTCCATGCAGTTCGACTCCTACGCCGAGGTTCCGCGGAACG'TCGCCGAGGAGA

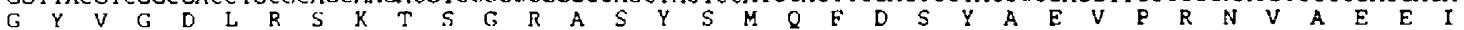

1001 ICATCGCGAAGGCCAAGGGCGAGTAACCCACCGCGTTCTCACGCCGTAGGCTTGACTCCGGAGTCTCGCGGGCCATTCATCCTCATATGCGGGTGAATGG I A K A K G E.

1101 CCCGGGGCCCGGGACTTAACAGCAAAGATCACCTGGCGCCGATTCAACCAAGGCGTACAGAACCACTCCACAGGAGGACCCCAGTGGCGAAGGCGAAGT A $X$ A K F

1201 CGAGCGGACTAAGCCGCACGTCAACATCGGCACCATCGGTCACATCGACCACGGTAAGACGACCCTCACGGCCGCCATTACCAAGGTGCTGCACGACGCG

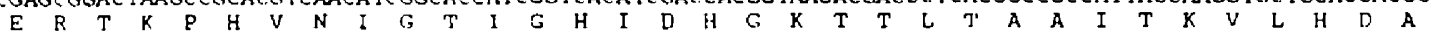

$13 \cup 1$ TACCCGGACCTGAACGAGGCCACCCCGTTCGACAACATCGACAAGGCTCCTGAGGAGCGTCAGCGCGG TATCACCA TC TCCATCGCGCACGTCGAGTACC

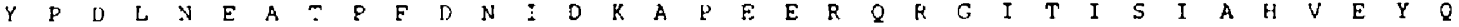

1401 AGACCGAGGCGCGICACTACGCCCACCTCGACTGCCCGCGTLACGCGGACTACATCAAGACATGATCACGGGTGCGGCGCAGATGGACGGCGCCATCCT $\begin{array}{lllllllllllllllllllllllllllllllll}T & \text { F } & A & \bar{R} & H & Y & A & H & V & D & C & P & G & H & A & D & Y & I & K & N & M & I & T & G & A & A & Q & M & D & G & A & I & L\end{array}$

1501 CGTGGTCGCCGCCACCGACGCCCCGATGCCGCAGACCAAGGAGCACGTGCTCCTGGCCCGCCAGGTCGGCGTTCCGTACATCGTGGTCGCCCTGAACAAG

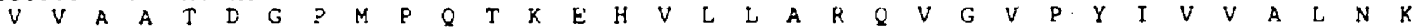

1601 GCCGACATGGTGGACGACGAGGAGATCA TGGAGCTCGTTGAGCTCGAGGTCCGTGAGCTCCTCTCCGAGTACGAGTTCCCGGGCGACGACCTGCCGGTCG A $D$ M V V D $D$ D E E I

1701 TCCGCGTCTCCGCGCTGAAGGCGCTGGAGGGCGACGCTCAGTGGACGCAGTCCGTCCTCGACCTGATGAAGGCCGTCGACGAGTCCATCCCCGGAGCCGGA

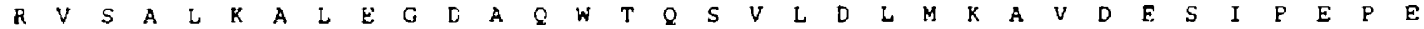

1801 GCGCGACGTCGACAAGCCGTTCCTCATGCCGATLGAGGACGTCTTCACGATCACCGGTCGCGGCACGGTCGTCACCGGCCGTATCGAGCGTGGTGTCCTG

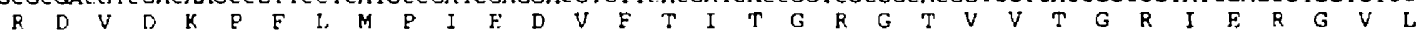

1901 AAGGTCAACGAGACCGTCGACATCATCGGCATCAAGACCGAGAAGACCACCACCACGGTCACCGGCATCGAGATGTTCCGCAAGCTGCTCGACGAGGGCC

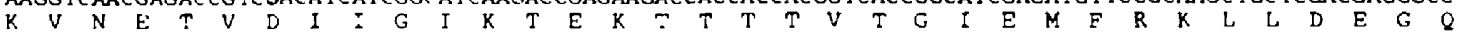

2001 AGGCCGGTGAGAACGTCGGTCTGCTGCTCCGCGGCATCAAGCGCGAGGACGTCGAGCGCGGCCAGGTCATCATCAAGCCGGGTCGGTCACCCCGCACAC $\begin{array}{llllllllllllllllllllllllllllllllllll}A & G & E & N & V & G & L & L & L & R & G & I & K & R & E & D & V & E & R & G & Q & V & I & I & K & P & G & S & V & T & F & H & T\end{array}$

2: 1 CGAGTFCGAGGCGCAGGCCTACATCCTCTCCAAGGACGAGGGTGG:CGCCACACGCCGTTCTTCAACAACTACCGCCCGCAGTTCTACTTCCGTACCACG



2201 GACGTGACCGGCGTTGTGCACCTCCCCGAGGGCACCGAGATGGTCATGCCGGGCGACAACACCGAGATGCGCGTCGAGCTGATCCAGCCCGTCGCCATGG

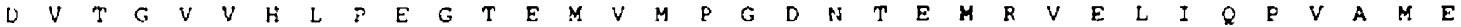

2301 AGGAGGGCTGAAGTTCGCCATCCGTGAGGGTGGCCGGACCGTCGGCGCCGGCCAGGTCACCAAGATCGTCAAGTAAGTTCCGCTTGCTTGAGGGTCGG,

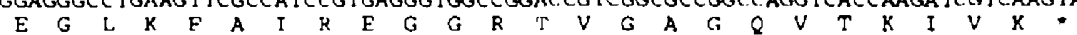

2401 TCTGACCAAGGCCTGTTGACCTCAAGGGGCCCGTACGACTGCGGTTGTGCGGGCCCCTITGCATGTGCGTGTCCATCAGGTGAACCTCTGGCGAACCCTG 2501 CCGCGCGGGGCCCGTGTGACGCCJGTGGCGGCCATAGAGTGACGCAGATGTTCGGCCAGGTCCCCGCTCGCAGCTCCGCCGCCCGCCCGCTGCCCCCGCT $260:$ CGTCCCGTCCCCGCGCAAGCCCGCCGCCGAGGCCCCCGTTCGCCGCCGCGAACGCTCCCGCCTGTACGCGGTCGACGGCATCCGGCTGCTCGCGGCCCTG 2701 ATCGTCGCCCTGCACCACTACGCCGGCACCCGCCGGGTGAACGCGI:CGGACAACGCGATCTGGGGCCGGCCGGTCTCCGAGA TCATGCCGACGACGTACC 2801 ACGTGGCCACGTACGGCTGGATCGGCGTCGAGATCT

Fig. 2. DNA sequences of (a) tuf-1, (b) tuf-2 and (c) tuf-3 from 5 . ramocissimus. The deduced amino acid sequences are indicated below the DNA sequence and the putative ribosome binding sites (AGGAGG for both tuf-1 and tuf- 2 , and GAGG for tuf-3) are underlined. Nucleotides 1-1026 in (a) code for the C-terminal part of EF-G. The nucleotide sequences are deposited in the EMBL Data Library, accession nos X67057 (tuf-1), X67058 (tuf-2) and X67059 (tuf-3).

GCG; programs Translate and Codonpreference (Devercux et al., 1984) which revealed two open reading frames (ORFs) (Fig. 2a). One ORF displayed a high degree of identity with the C-terminal part of the E. coli fus gene, encoding EF-G (Zengel et al., 1984) and the other with tuf $A$ (Yokota et al, 1980). The latter ORF codes for a 


\section{(b) tuf-2}

GGATCCCGGCGAACATCACCACGAGCACCAGGACGATCGCGGCGACCACC TTCGCCCAGCCGGGCACGCGCCGCAGGCCGCGCCGGTCCGCGGGCGTCCT 101 GACGGAAGTCOTCATGTCGACCGTCCTCCTTC CTGTTCACACGGATTCCCCGCCAACCGC CGGGCCAGACACCGCTGTTGCGAACTCCATGCGCACAACG 201 CGTGTCCGCCGGCGCCCTGTTCGGCACOGCGTGGAGCGAATACACACCAACGTGGAGCCAATACACAGGAAGAAGACACGGCATCCCCGGCATCACCCC 301 AGGTCACCACGAGGGCCCGCAG.GGCGAAGGGAAGTCCAGCGGACCAAACCCACGTCAACATCGGCACCATCGGCCACATCGACCACGGCAAGACGA

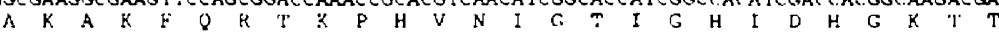



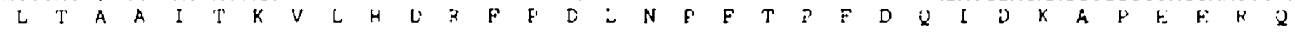

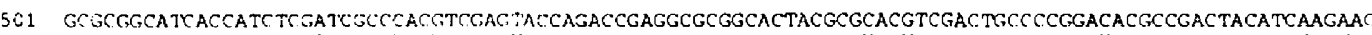
R G I T I S I A H V E Y O T E A R H Y A H V D C Y G H A D Y I K N

601

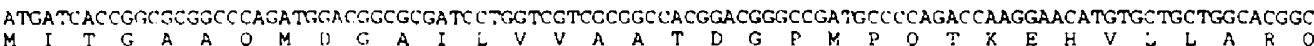

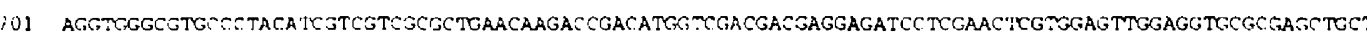

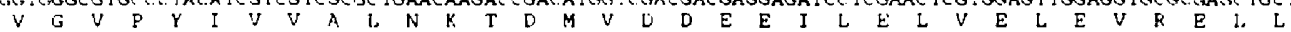

80: CACCGAGTACGAGTTCECCGGCGACGACGICCCGGTCGTCAAGGTGTCGGCGCTCACGGCOC TGGAGGGCGACCCCCGOTGGACCCGGTCGGTACTCGA

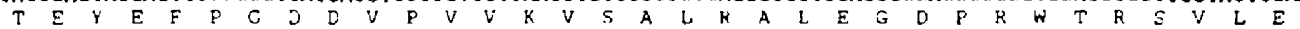

90: CTCCTCGACGCCGTCGACGACIIITGTGCCCGAGCCGGICCGGGACGTCGACCGGCCGTTCCTGATGCCGATCGAGGACGTCTTCACCATCACCGGACGCG

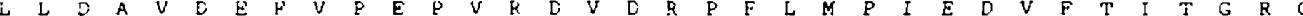

100: GCACGCXCTCACCGGCCGGATAGAGCGCGGCACGCTGAACGTGAACACCGACGTGGAGATCATCGGCATCCACGAACAGAGGACCCGGACCACGGTCAC $\begin{array}{llllllllllllllllllllllllllllllllllll}T & V & V & T & G & R & I & F & R & G & T & L & N & V & N & T & E & V & E & I & I & G & I & H & E & Q & R & T & R & T & T & V & T\end{array}$

20: CGGCATCGAGATGTTCCGCAAGCTCC TCGACGAGäCCGGGCOGGCGAGAACGTCGGACTGCTGCTGCGCGGAGTGMAGCCCGAGCAGGTCGAGCGCGG'T

$120 \mathrm{i}$ CAGGTCGTCATAACOCCOGATCGSTCACCCCGCACACGCAGTTCGAGGCGCAGGCGIACATCCTGTCCAAGGACGAGGGCGGCCGGCACACGCCGTTCT

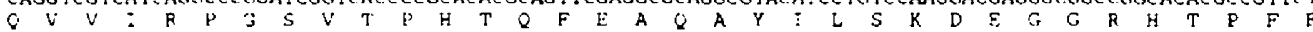

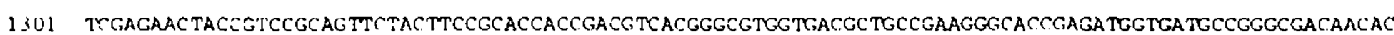

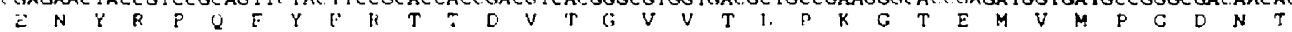

1401 GGCCATGCACCTCCAGCTCATCCAGCCGATCGCCATGGAGGAGGGCTGAAGTTCGCCATCCGCGAGGGCGGGCGCACGGTCGGCGCCCGCCAGGTCACC

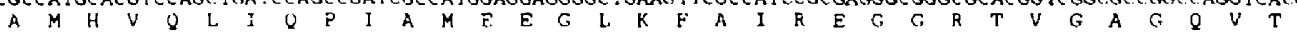
1501 CGGATCGTGAAGTAGCCCTGZTCTGACCCGAAACAGCSGCTGCGCGGTGTGAAACAGCCCCCGTCATAAGGAGCCTGACGCGGCGTCGGGCTGGCCCAGG

1601 GCCGCGJCAGGCTCGGCGCGGGCGCCACAGCCGGGTCAGCCCGJGGGCGCAGACGCGAGCTAACGATGGTECACACGA

\section{(c) tuf-3}

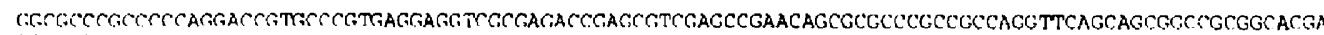

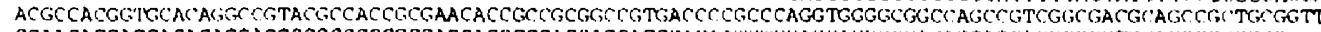

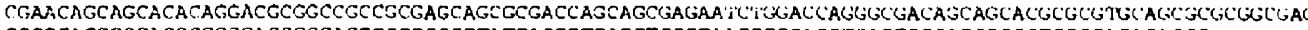
CCCGGACGGCGACGCGGGGACGGCGACGGCC,CCCGTATGACGGTGAGCTCCGTAAGGC,CAGCTCAGTGOCAGCGGC CTGGGGAGAGACCGCGGCGGTC

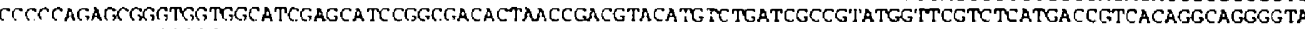
CGGTCGGCGTACCGGCCGGCGCGCTCGCCGACACGACCCCCGTGCGGCGCGCGCTCTCCOGCACCGTCCTCGACGGCACGCCCCGCCCCCACCAAGACCGA

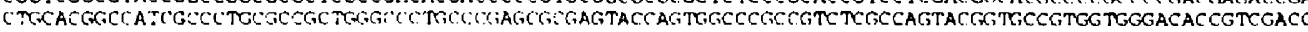
TGCTGGCCCCACATGTCGTGGGCGCC CTGG.TGC CGCCGACCCGGCGCTGAAGGCGGACATGGACGCCTICAGCGTGGACGACGACCTCCCGATCGTCCC TACCGCCOTCCCCACCAATGCGGGAGCCOCTRAAGAACATCGGCGCC TGACATCGCGTGTCGCTGAAGTCCCGTACCGCDGAAAACCATTCGACGTCG

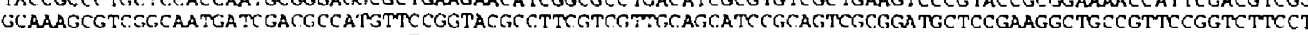
GGCCGCATTCGACGGCGCCCGAAGCTGACCCTCTCCGGACAGTCCGGCGGACCCCGCAGGGGGAGGTCGGCGAGTCCTCGGGGTCCCCGATCTCCTTCO TAGAGACTTCGAGGTACAGCCATGTCCAAGACGGCATACGTGCGACCAAACCGCATCTGAACATCGGCACGATGGGTCATGTCGACCACGGCMAGACCA $S \quad K \quad T$ A

1201 CGTTGACCGCCGCCATCACCAAGGTCCTCGCCGAGCGTGGCTCCGGGACGTTCGTCCCGTTCGACCGCATCGACCGGGCCCCGGAGGAGGCCGCGCCCCO

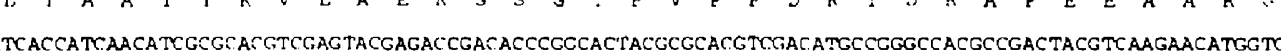

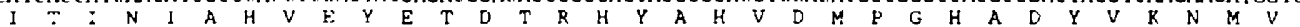

2401 ACCGGCGCCGCGCAGCTCGACGGGGCGATCCTCGTTGTCTCCGCGCTCGACGGGATCATGCCGCAGACCGCCGAACACGTCCTGCTCGCCCGGCAGGTGG

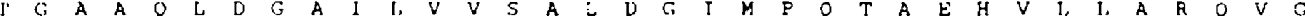

:501 GCGTCGACCACATCGTCGTCGCCCTChACAAGGCCCACGCGGGCGCGAGGACC TCACCGACCTCGTCGAGCTGGAGGTCCGCCATCTCCTCICCGAGCA

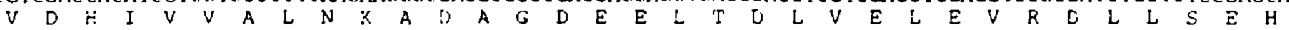

1601 CGGCTACGGCGCCGACGGTGCCCCCGTCG?ACGGGTCTCGGGGC'TGAAGGCGCTGGAGGGCGACCCCAAGTGGACGGCGTCCATCGAGGCGCTGCTCGAC

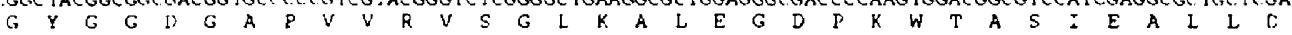

$1 \% 1$ GCGGTGGACACCTACGTGCCGATGCCGCAGCGGTATGTGGACGCGCCGTTCCTGCTGCCCGTGGAGAaCGTGCTCACCATCACCCGTCGCCCCACCGTCO

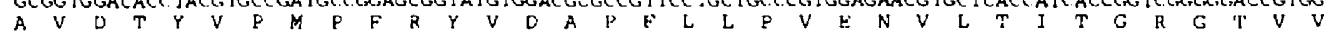

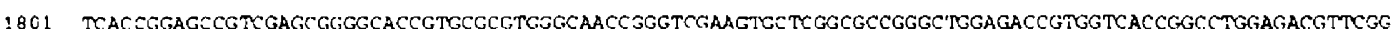
$T$ G A V V F

1901 CAAGCCCATGGACGAGGUOCAGGCOGGGGACAACG?GGGCTGTTGCTGCCIGGGG:TCCGGGGACGCCGTACGGCGTGGGCATGTGGTCGGGCGCCG

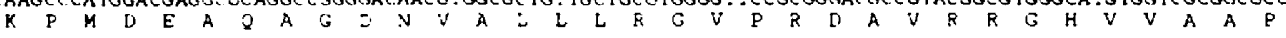

2001 GGGAGCGTEGTGCCECGGASTCGATTCTCCGCGCAGGTGTATGTCCTC'TCCGCCCGCGAGGGCGGTCGTACGACTCCTGTCACCAGCGGGTATCGGCCGC

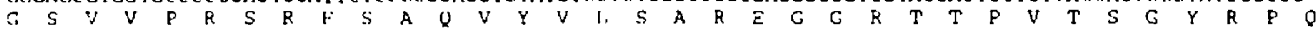
2101 AGTTCTACATCCOTACGGCOGATGTGGTGCGGCACGTCGACCTGGGGGAGGTGGGGGTCGCTCGGCCTGGGGAGACOGTTTCGATGATCGTCGACTTCGC





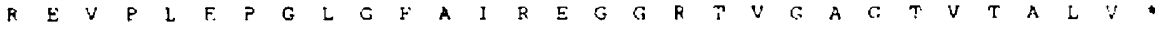

2301 ACGGGCGTGGGGACTGCGGGGCCGTCGTGGCTGGCGCGCAGTCCCCGCGCCCCIITTTGTCGGACCGGCCAGGCAACAATTGGAAGGTGAACGACGC 2401 CATCCCTGTCTCCCGTGCCGTTGA TITCGGGACTGCCAAGCTGATGCCCGACGTCGATCGAGAGCG $3 G C C T G G G$ TGCTCACCGTCGACGGGGCTCCGCAG 2501 TCCTACGTCGATCPCGACGACCCGGCCTACCTGGAGTTCGAGTACGCCCAGCGGCTCGGGCATGTGCTCGACATCC TIGCGGACGCCGGTCACGCC TGGA 2601 CGTCGTACACCTCGGTGGGGGTGCCTGCACTCTSCCCCCGTATCTCGCCGCCACCCCGCCCGGGTCCCGGCAGGAAGTCGTCGAGGCCGACGGSGGGCTG 2701 CTGGAGCTGGTCGCCGAAGTGTTGCCGTHEC 
protein of 396 amino acids, designated (Sr.)EF-Tu1 (see Fig. 3). A probe derived from the C-terminal part of the fus gene present on the cloned $B g / I I$ fragment gave a single signal in the Southern blot. This probing also showed that the $2.8 \mathrm{~kb} \mathrm{Bg} / \mathrm{II}$ fragment is part of the $5.2 \mathrm{~kb} \mathrm{BamHI}$ and of the $6.2 \mathrm{~kb}$ Pst I fragment (data not shown). Partial sequencing of the $6.2 \mathrm{~kb}$ PstI fragment and hybridization studies suggest that the gene organization on this part of the $S$. ramocissimus genome is $r p s \mathrm{~L}-r p s \mathrm{G}-f u s-t u f$, identical to that of E. coli (Post et al., 1980), Spirulina platensis (Buttarelli et al., 1989), Micrococcus luteus (Ohama et al., 1987) and Anacystis nidulans (Meng et al., 1989) (data not shown). To gain more insight into the nature of the fragments that hybridized more weakly with the E. coli tuf $A$ probe (Bam HI fragments of 2.8 and $12 \mathrm{~kb}$ and $P s t \mathrm{I}$ fragments of 4.3 and $15 \mathrm{~kb}$ ), the Southern hybridization experiment was repeated with probes from the $\mathrm{N}$-terminal and $\mathrm{C}$-terminal part of the $S$. ramocissimus tuf- 1 gene. Both probes hybridized with each of the four fragments, indicating that they contain complete tuf-like genes.

A tuf-1 probe that gave a stronger signal in the Southern analysis than the E. coli tuf $A$ probe was used to clone the $2.8 \mathrm{~kb} \mathrm{BamHI}$ fragment and a $9 \mathrm{~kb}$ EcoRI-Bam HI fragment. The $2.8 \mathrm{~kb}$ Bam HI fragment carries an ORF corresponding to a protein of 396 amino acids, whereas the $9 \mathrm{~kb} B a m \mathrm{HI}-E c o \mathrm{RI}$ fragment carries an ORF corresponding to a protein of 388 amino acids (Figs $2 b, c, 3$ ). The genes were designated tuf-2 and tuf- 3 and their products Sr.EF-Tu2 and Sr.EF-Tu3, respectively, although we do not know whether they encode genuine EF-Tus.

\section{Nucleotide and amino acid sequence comparisons}

Degrees of nucleotide sequence identity of the three $S$. ramocissimus tuf-like genes and $E$. coli tuf $A$ are listed in Table 1. Most strikingly, the $S$. ramocissimus tuf genes display a much lower degree of similarity than do the two E. coli tuf genes $(99 \%)$, which differ at four base positions only. The nucleotide sequence of tuf-3, encoding the GDP-binding domain (amino acids 1-200), has 76\% identity with the corresponding sequences of tuf- 1 and tuf2. The identity drops to $63 \%$, however, for the sequence encoding the C-terminal part of the protein. This drop in identity coincides with a change in the codon usage towards favouring codons with $\mathrm{A}$ or $\mathrm{T}$ in the third

Table 1. Nucleotide sequence comparison of the three $S$. ramocissimus tuf-like genes and $E$. coli tufA.

\begin{tabular}{|cccc|}
\hline & \multicolumn{3}{c|}{$\%$ identical } \\
\cline { 2 - 4 } & tuf-1 & tuf -2 & tuf-3 \\
\hline tuf-1 & & 85 & 70 \\
tuf-2 & & & 70 \\
tuf $A$ & 71 & 69 & 63 \\
\hline
\end{tabular}

position, which is unusual for Streptomyces. Obvious deviations from the codon usage often found in genes with a high level of expression (Wright \& Bibb, 1992) are not observed in tuf-1 and tuf-2. However, it is noteworthy that tuf- 1 , but not tuf-2 and tuf-3, has a high percentage of GGT codons for Gly, as has also been observed for the ribosomal protein L7/L12 of $S$. antibioticus (Parra et al., 1992).

Both tuf-1 and tuf-2 are preceded by putative ribosome binding sites with $6 / 6$ homology to the $3^{\prime}$ end of known $16 \mathrm{~S}$ rRNA sequences (van Wezel et al., 1991, and references therein). In the case of $t u f-3$ this fit is only $4 / 6$ (Fig. 2c). A search for promoter sequences upstream of the three tuf genes using the Streptomyces promoter consensus sequence described by Strohl (1992) was unsuccessful. Sequences upstream and downstream of the genes were analysed for identity with known sequences in the databases. A positive result was obtained only in the case of the tuf-1 upstream region where the fus gene, encoding EF-G, was localized.

In Fig. 3 the deduced amino acid sequences are compared with the $E$. coli $\mathrm{EF}-\mathrm{Tu}$ sequence since most of the data regarding structure/function relationships concern the $E$. coli protein. All three Streptomyces proteins contain the consensus sequence typical for GDP-binding proteins (Dever $e$ t al., 1987) and show a $100 \%$ fit with the P-loop motif (Saraste et al., 1990). The Ec.EF-Tu amino acid residues His-66, Lys-208 and Lys-237 (underlined in Fig. 3 ) that have been cross-linked to tRNA (Duffy et al., 1981; van Noort $e t$ al., 1984) are conserved in EF-Tu1 but not in EF-Tu2 or EF-Tu3. Lys-56 of Ec.EF-Tu, which has been found to be methylated in the late exponential phase and stationary phase (van Noort $e t$ al., 1986), is not present at that position in any of the three. All amino acid residues known to be altered in kirromycin-resistant mutants are conserved in the three Sr.EF-Tus (see Discussion). On the other hand, Lys-357 of Ec.EF-Tu, previously cross-linked to kirromycin (van Noort et al., 1984) is not conserved.

The results of a comparison between the deduced amino acid sequences of the three Sr.EF-Tus and some of the known EF-Tu sequences of almost all the phyla in the eubacterial kingdom, one representative of the archaebacteria and two eukaryotes are shown in Table 2. Sr.EFTu1 and Sr.EF-Tu2 are more closely related to each other than to any of the other sequences listed in Table 2. This suggests that the genes were derived relatively recently from a common ancestral gene. In contrast, the similarity between EF-Tu3 and EF-Tu1 or EF-Tu2 is only slightly higher than with any of the other eubacterial EF-Tus. The degree of identity of EF-Tu3 to each of these other eubacterial EF-Tus is about the same, but much higher than to the archaebacterial or eukaryotic EF-1 $\alpha$ species. So, although a relationship of EF-Tu3 with the EF-Tus from the same organism is not apparent, EF-Tu3 clearly belongs to the eubacterial lineage. This is consistent with the finding that the three Sr.EF-Tus show the same degree of identity/similarity with the EF- $1 \alpha$ species of Rhizomucor racemosus and Xenopus laevis. Interestingly, EFTu3 shows a somewhat closer relationship with Thermo- 
EF-TU1

EF-TU2

EF-TU3

EF-TuA

1 AKAKFERTKPHVNIGTIGBIDEGKTTLTAAITKVLHDAYPDLNEATPFDN

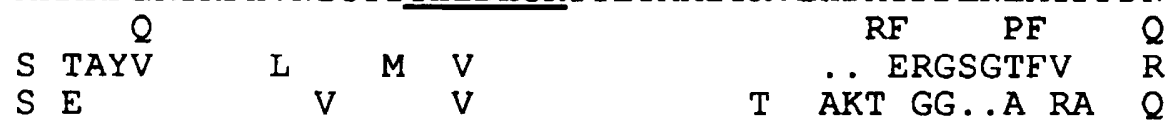

51 IDKAPEERQRGIT IS IAHVEYQTEARHYAHVDCPGEADY IKNMITGAAQM

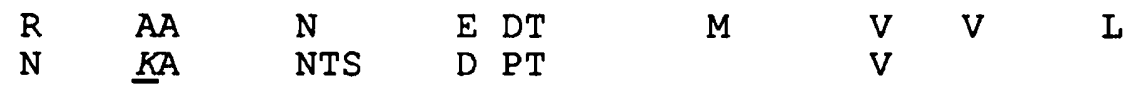

101 DGAILVVAATDGPMPQTKEHVLLARQVGVPYIVVALNKADMVDDEEIMEL
S L I
$\begin{array}{lll}A & & \\ R & I & G\end{array}$
$\mathrm{DH}$
T $L$
L

151 VELEVRELLSEYEFPGDDLPVVRVSALKALEGDAQWTQSVLDLMKAVDES

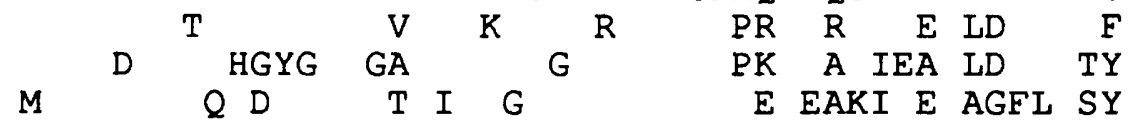
201 IPEPERDVDKP FLMP IEDVFT ITGRGTVVTGRIERGVLKVNETVDIIGIK $V \quad V \quad \bar{R} \quad T \quad \bar{N} T E \quad E \quad H$ $\begin{array}{lllllll}V & Y & A & \text { I } V & N & \text { I } & \text { AV TVR GNR EVI AG }\end{array}$ AI $\quad \mathrm{L}$ S S V II G E E V

251 TEKTTTTVTGIEMFRKLLDEGQAGENVGLILRGIKREDVERGQVIIKPGS

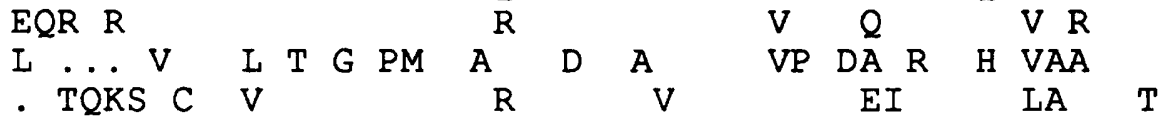

301 VTPHTEFEAQAYILSKDEGGRHTPFFNNYRPQFYFRTTDVTGVVHLPEGT

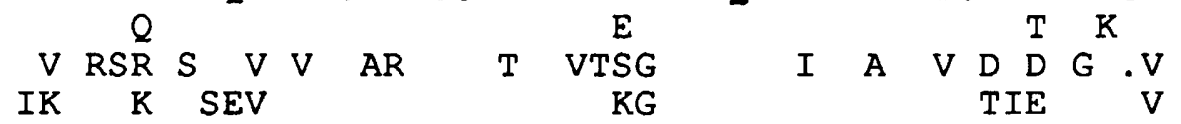

351 EMVMPGDNTEMRVELIQPVAMEEGLKFAIREGGRTVGAGQVTKIVK 396

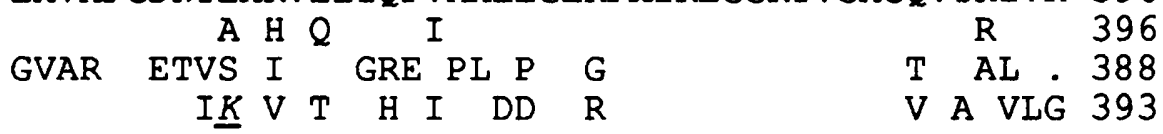

Fig. 3. Amino acid sequences of EF-Tu1, 2 and 3 from S. ramocissimus and EF-TUA from $E$. coli aligned with the GAP program of the Wisconsin GCG sequence analysis package (Devereux et al., 1984). The GDP binding consensus sequence is underlined and in bold. The residues corresponding to the Ec.EF-Tu amino acids involved in tRNA interaction are underlined in the EF-Tu1 sequence. The amino acids changed in kirromycin-resistant $E$. coli EF-Tus are indicated in bold. The residues Lys-56 and Lys-357 which are sometimes methylated in EF-TuA are printed in italic and underlined.

coccus celer EF-Tu than do EF-Tu1 and EF-Tu2. The unusual sequence data of EF-Tu3 prompted a search for tuf-3 homologues in Streptomyces spp. and other bacteria.

\section{Number of tuf-like genes in other Streptomyces species}

The presence of three tuf-like genes in S. ramocissimus raised the question whether this is a particular feature of this species or a more general gene arrangement of Streptomyces. We therefore analysed chromosomal DNA of several Streptomyces species digested with Pst I and BamHI by probing the Southern blot with a fragment internal to the coding sequence of $t u f-1$ (Fig. 4a), of $t u f-2$
(Fig. 4b) and of tuf-3 (Fig. 4c). The signals in (a) correspond to tuf-1 homologues in the various strains. The signals in (c) are $t u f-1$ [cf. (a)] and $t u f-3$ homologues. In addition some weaker signals can be observed which have not been characterized further. The tuf- 2 probe in (b) does not reveal tuf-2 homologues in any of the strains except for $S$. ramocissimus. The stronger signals correspond to $\operatorname{tuf}-1$ [cf. (a)] and the weaker signals to $\operatorname{tuf}-3$ [cf. (c)].

\section{Heterologous expression of the tuf-like genes in E. coli}

Expression of tuf-1. Transformation of E. coli with pUSRT1-1 (Fig. 5a) did not result in good heterologous 
Table 2. Amino acid sequence comparison of the three tuf gene products of $S$. ramocissimus with representatives of the various kingdoms.

Compare Woese (1987) for the phylogenetic tree. Amino acid sequences were retrieved from the Swiss Protein Data Library and aligned with the GAP program of the Wisconsin GCG sequence analysis package (Devereux et al., 1984). References: 1, Ohama et al. (1987); 2, Yokota et al. (1980); 3, An \& Friesen, 1980; 4, Seidler et al. (1987); 5, Satoh et al. (1991); 6, Bachleitner et al. (1989); 7, Mickel \& Spremuli (1986); 8, Buttarelli et al. (1989); 9, Loechel et al. (1989); 10, Kraus et al. (1990); 11, Auer et al. (1990); 12, Sundstrom et al. (1987); 13, Djé et al. (1990); 14, Deschamps et al. (1991).

\begin{tabular}{|lccc|}
\hline & \multicolumn{3}{c}{$\%$ identical; \% similar } \\
\cline { 2 - 4 } & EF-Tul & EF-Tu2 & EF-Tu3 \\
\hline Eubacteria & & & \\
S. ramocissimus EF-Tu1 & 100 & $88 ; 94$ & $65 ; 78$ \\
S. ramocissimus EF-Tu2 & & 100 & $64 ; 78$ \\
Micrococcus luteus (Gram-pos., high GC) (1) & $79 ; 87$ & $77 ; 87$ & $61 ; 76$ \\
E. coli (purple bacteria) (2,3) & $74 ; 85$ & $72 ; 84$ & $60 ; 77$ \\
Thermus aquaticus (thermophiles) (4,5) & $71 ; 84$ & $71 ; 84$ & $63 ; 77$ \\
Thermatoga maritima (6) & $70 ; 84$ & $69 ; 84$ & $63 ; 80$ \\
Anacystis nidulans (cyanobacteria) (7) & $70 ; 83$ & $67 ; 82$ & $60 ; 75$ \\
Spirulina platensis (cyanobacteria) (8) & $70 ; 82$ & $67 ; 80$ & $59 ; 75$ \\
Mycoplasma genitalium (Gram-pos., low GC) (9) & $69 ; 82$ & $67 ; 80$ & $60 ; 74$ \\
Cyanophora paradoxa (cyanelle) (10) & $68 ; 81$ & $65 ; 80$ & $59 ; 75$ \\
Archaeobacteria & & & \\
Thermococcus celer (11) & $39 ; 61$ & $38 ; 60$ & $40 ; 63$ \\
Eukaryotes & & & \\
Rhizomucor racemosus (12) & $33 ; 57$ & $33 ; 57$ & $35 ; 57$ \\
Xenopus laevis, 42Sp50 (13,14) & $33 ; 52$ & $33 ; 52$ & $34 ; 54$ \\
Xenopus laevis, EF-1 $\alpha$ S and EF-1 $\alpha \mathrm{O}(13,14)$ & $33 ; 57$ & $32 ; 57$ & $34 ; 55$ \\
\hline
\end{tabular}

expression of $t u f-1$ in cells during exponential growth (i.e. 1 and $2 \mathrm{~h}$ after induction). Highest expression was observed $16 \mathrm{~h}$ after induction, when the cells were in the stationary phase (Fig. 6). Further analyses were then performed with immunoblotting using antibodies raised against EF-Tu isolated from $S$. ramocissimus. The Western blot of Fig. 7 (lanes 1 and 2) shows that this EF-Tu migrates to the same electrophoretic position as the product of $t u f-1$, isolated from stationary phase E. coli cells after heterologous tuf-1 expression. Therefore, we conclude that the EF-Tu species isolated from $S$. ramocissimus is the product of tuf-1. Both EF-Tu1 isolated from $S$. ramocissimus and the product of tuf -1 , heterologously expressed in E. coli are able to participate in poly(Phe) synthesis in vitro and are inhibited by kirromycin (Fig. $8 \mathrm{a}, \mathrm{b}$ ). Kirromycin sensitivity (EF-Tu1) was dominant over kirromycin resistance (EF-Tu of $E$. coli strain PM1455) and therefore inhibition of poly(Phe) synthesis was observed (Fig. 8b).

Expression of tuf-2. For the expression of tuf- 2 in E. coli two recombinant plasmids were constructed, pUSRT2-1 and pUSRT2-3 (Fig. 5b). Expression of tuf-2 in JM101 transformed with pUSRT2-1 could not be demonstrated (Fig. 7, lane 3). In overnight cultures of JM101 transformed with pUSRT2-3 which has part of the tuf-2 upstream sequence deleted, tuf-2 expression was detectable (Fig. 7, lane 4). The heterologous expression of tuf-2 was substantially lower than that of tuf- 1 . It could only be detected on Western blots and not in Coomassie Brilliant Blue stained gels. Moreover, about $80 \%$ of the tuf -2 product was found in so-called inclusion bodies, which are spun down at $30000 \mathrm{~g}$ (data not shown). The expression was too low for purification, functional characterization and immunization. Although EF-Tu2 has the same number of amino acids (396) as EF-Tu1, it migrates considerably faster during SDS-PAGE (Fig. 7, lanes 2, 4 and 5), which made distinction between the two factors in $S$. ramocissimus extracts possible.

Expression of tuf-3. Expression of the tuf-3 gene could not be demonstrated in JM101 cells transformed with pUSRT3-1 (Fig. 5c). Sequences immediately upstream of the putative ribosome binding site (GAGG, nt 1111-1114, Fig. 2c) of the $t u f-3$ gene were deleted to remove potential transcriptional termination signals. This did not result in appreciable expression either. The ribosomal binding site of tuf-1 was then cloned upstream of tuf-3, yielding the plasmid pUSRT3-3 (Fig. 5d). This resulted in very high expression of $t u f-3$ in the E. coli strain KA797 (Fig. 9, lanes 1 and 2). More than $90 \%$ of the tuf-3 gene product appeared to reside in inclusion bodies. We failed to alter 


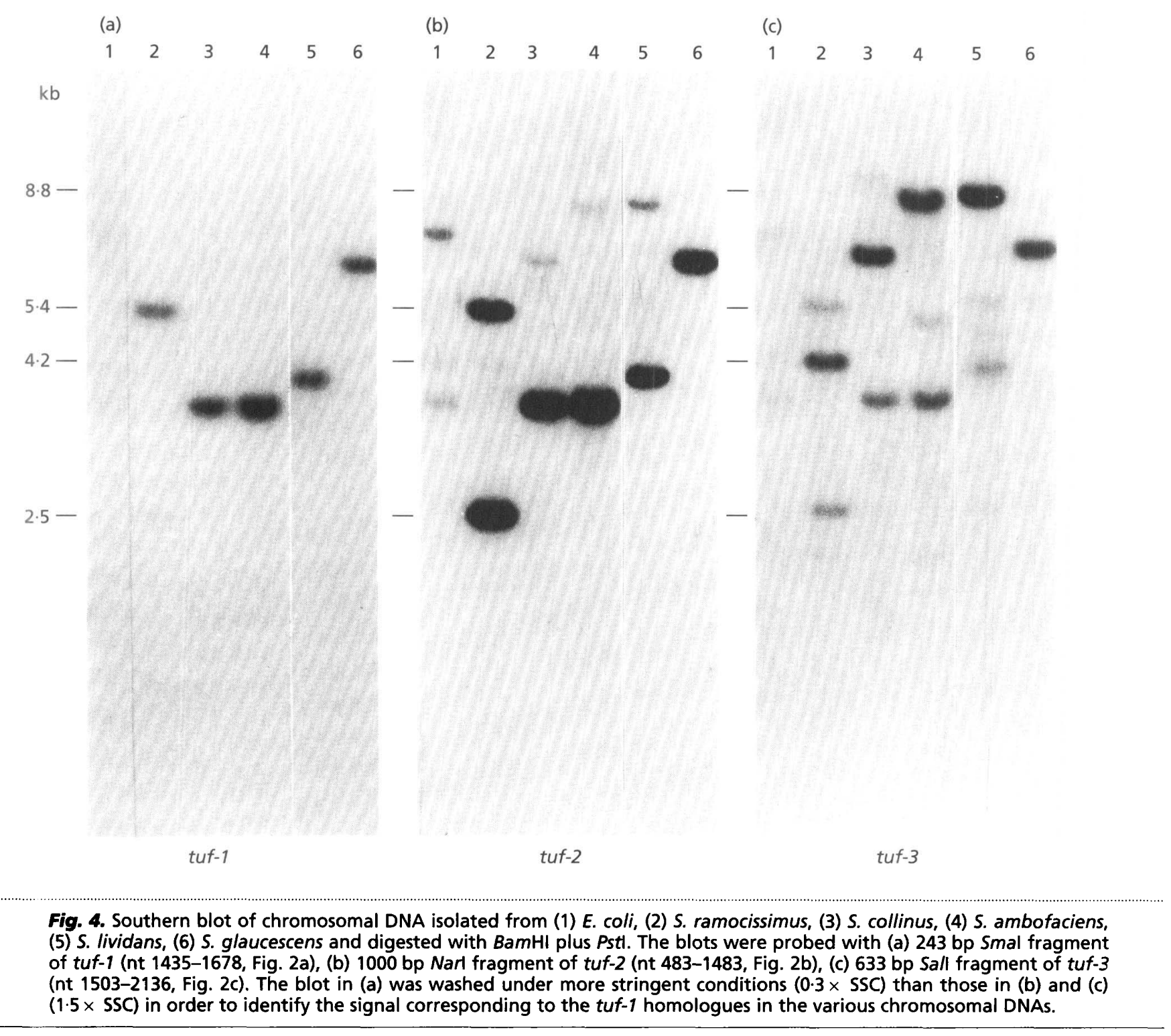

this subcellular distribution of the product by varying the culturing conditions, such as lowering temperatures and shortening growth and periods of induction by IPTG. To solubilize the tuf-3 gene product pellets were treated with $4 \mathrm{M}$ urea and $100 \mu \mathrm{g}$ lysozyme $\mathrm{ml}^{-1}$ according to Frankel et al. (1990) and centrifuged at $30000 \mathrm{~g}$. The tuf-3 gene product now appeared in the $\mathrm{S} 30$ supernatant and remained soluble after removal of urea by passing the supernatant through Sephadex G-25 (PD10 column, Pharmacia). The eluate of this column was submitted to agarose gel electrophoresis and the tuf-3 gene product isolated by freeze-sweeping. The tuf- 3 product thus obtained was homogeneous as judged by SDS-PAGE (Fig. 9, lane 4) and migrated slightly faster than E. coli EFTu (Fig. 9, lane 5) but significantly faster than EF-Tu1 (Fig. 9, lanes 3 and 4). Activity of the protein, however, could not be demonstrated with in vitro assays. Polyclonal antibodies raised against the $t u f-3$ product showed crossreactivity towards EF-Tu1 and heterologously expressed tuf-2 product. The tuf-3 product, however, is not recognized by anti-EF-Tu1 (data not shown).

\section{Homologous expression}

The availability of antibodies raised against EF-Tu1 enabled us to study its synthesis and that of EF-Tu2 under various conditions in $S$. ramocissimus. The antibodies raised against the $t u f-3$ product enable the detection of all three EF-Tus. That they also recognize EF-Tu3 produced in Streptomyces was demonstrated by putting tuf- 3 behind the constitutive ermE promoter on the plasmid pI J4090 (J. White \& M. J. Bibb, unpublished), resulting in pISRT3-1. Over-expression had to be studied in $S$. coelicolor M145 since a suitable transformation system for $S$. ramocissimus was not found. Submerged cultures of pISRT3-1 transformants of $S$. coelicolor were grown in TSB medium for $24 \mathrm{~h}$. S30 extracts were then submitted to immunoblotting, using the antibodies against the $t u f-3$ 
(a)

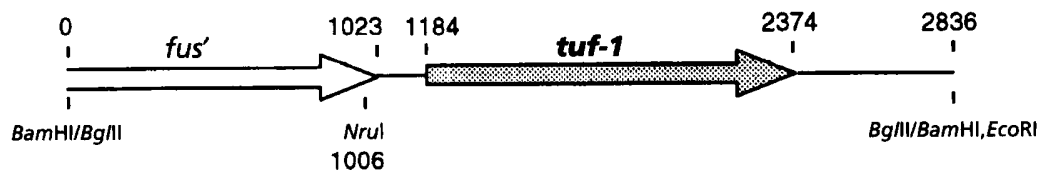

(b)

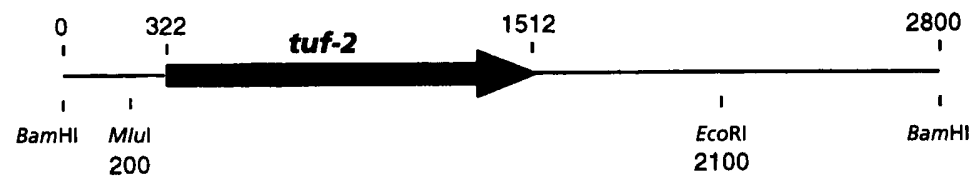

(c)

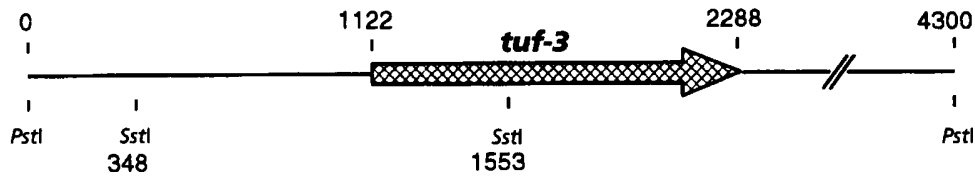

(d)
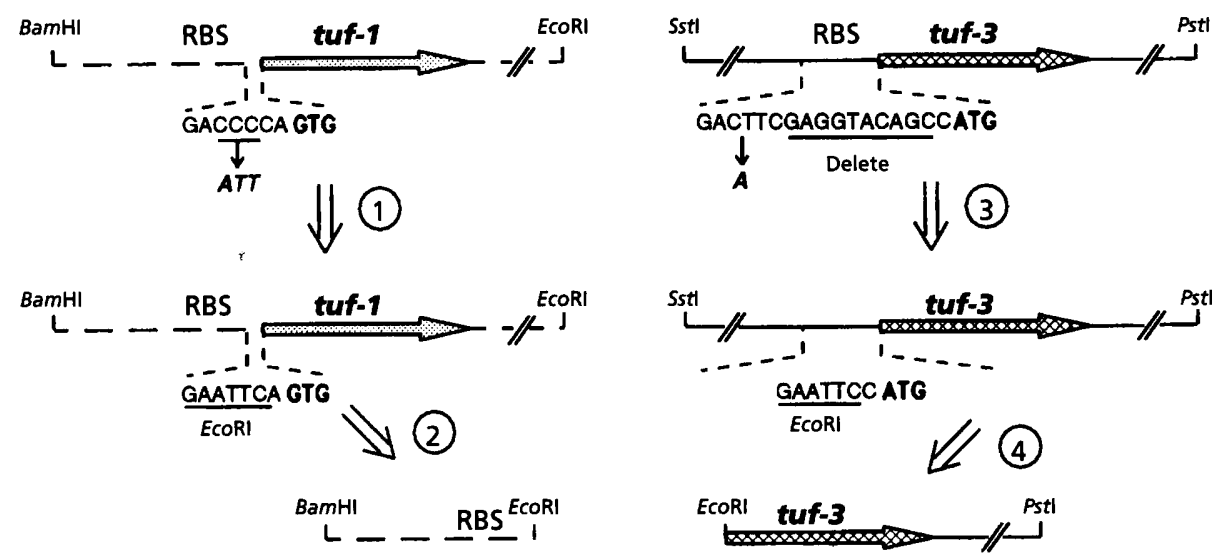

$\Downarrow(5)$

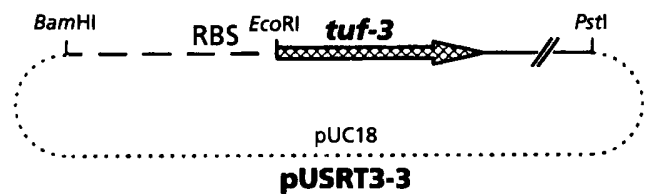

Fig. 5. Construction of plasmids for heterologous expression. (a) pUSRT1-1. A $1.8 \mathrm{~kb}$ Nrul(1006)-EcoRI(2836) fragment containing the entire tuf-1 gene was subcloned from the $2.8 \mathrm{~kb}$ Bg/lI fragment of pUSRT1 in Smal- and EcoRI-digested pUC19 (Yanisch-Perron et al., 1985). The Nrul site is located $180 \mathrm{bp}$ upstream of the GTG start codon of tuf-1 and the EcoRI site is from pUC19, adjacent to the Bg/lI/BamHI ligation site. (b) pUSRT2-1. From the $2 \cdot 8 \mathrm{~kb}$ BamHI fragment containing the entire tuf-2 gene, a BamHI(0)-EcoRI(2100) subclone was constructed in pUC19. pUSRT2-3. PUSRT-2 was digested with Mlul(200) and the protruding $3^{\prime}$ ends were converted to blunt ends by T4 DNA polymerase. After digestion with EcoRl, the fragment harbouring tuf-2 was cloned in Smal-EcoRI-digested pUC19 resulting in pUSRT2-2. In order to ensure that translation, starting at the ATG of lacZ in pUC19, did not continue into tuf-2, the $5^{\prime}$ protruding ends of HindIII (site in the polylinker of pUC19 and upstream of the tuf-2 fragment) -digested pUSRT2-2 were filled and ligated. The plasmid pUSRT2-3 contains a stopcodon (TAG) located at the position of the original HindIII site and in frame with the lacZ start. (c) pURST3-1. This was constructed by partially digesting PASRT3 with Sstl and with Pstl. The Sst1(348)-Pstl(4300) fragment was subcloned in pUC18. (d) pURST3-3. In order to replace the ATG upstream region of tuf3 by that of the tuf-1 GTG upstream region, EcoRI sites were constructed immediately in front of the translation start codons (steps 1 and 3). The final construct pUSTR3-3 was isolated after a three fragment ligation: BamHI-EcoRI (tuf-1 upstream region), EcoRI-PstI (containing tuf-3), and BamHI-Pstl-digested pUC18 (steps 2, 4 and 5). All base changes were made by oligonucleotide-directed mutagenesis according to Kunkel et al. (1990) and confirmed by sequencing. 


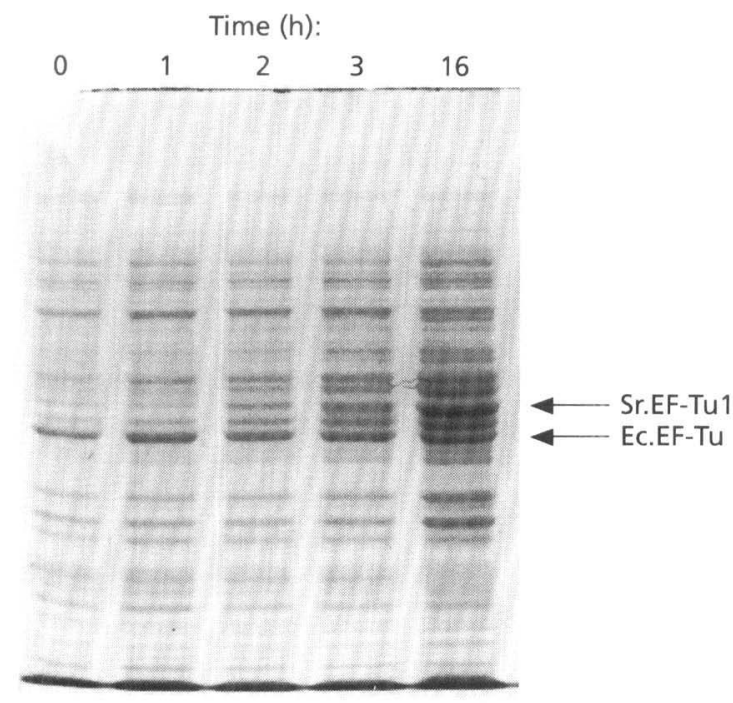

Fig. 6

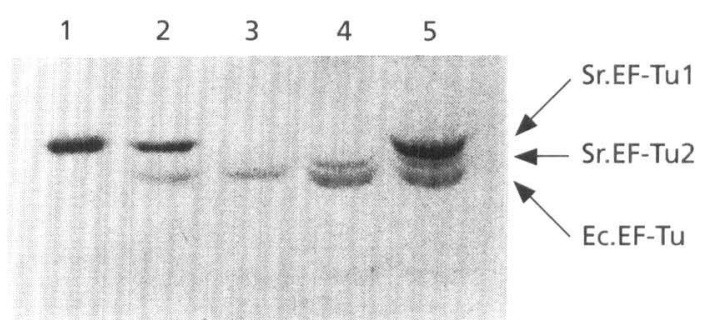

Fig. 7

Fig. 6. Temporal expression of tuf-1 in E. coli JM101 studied with SDS-PAGE. E. coli JM101 transformed with pUSRT1-1 was grown in LB broth at $37^{\circ} \mathrm{C}$. The expression of tuf-1 was induced by the addition of $0.5 \mathrm{mM}$ IPTG at OD 600 0.2 . The indicated times are relative to the addition of IPTG $(=0 \mathrm{~h})$. Total cell extracts were subjected to SDS-PAGE. The gel was stained with Coomassie Brilliant Blue. The sample in lane 0 was taken immediately before the addition of IPTG. The positions of EC.EF-Tu and Sr.EF-Tu1, as indicated in the figure, were identified in Western blots with antibodies raised against Sr.EF-Tu.

Fig. 7. Expression of tuf-1 and tuf-2 in E. coli JM101 (16 h induced with IPTG) studied with immunoblotting using antibodies raised against EF-Tu1 isolated from $S$. ramocissimus. The tuf gene products observed in each lane are, from top to bottom. Lane 1, EF-Tu1 purified from S. ramocissimus; lane 2, EF-Tu1 and Ec.EF-Tu, total extract of E. coli JM101 PUSRT1-1; lane 3, Ec.EF-Tu, total extract of E. coli JM101 pUSRT2-1; lane 4, EF-TU2 and Ec.EF-Tu, total extract of E. coli JM101 pUSRT2-3; lane 5, EF-TU1, EF-TU2 and EC.EF-Tu, mixture (1:1) of samples applied in lane 1 and 4.

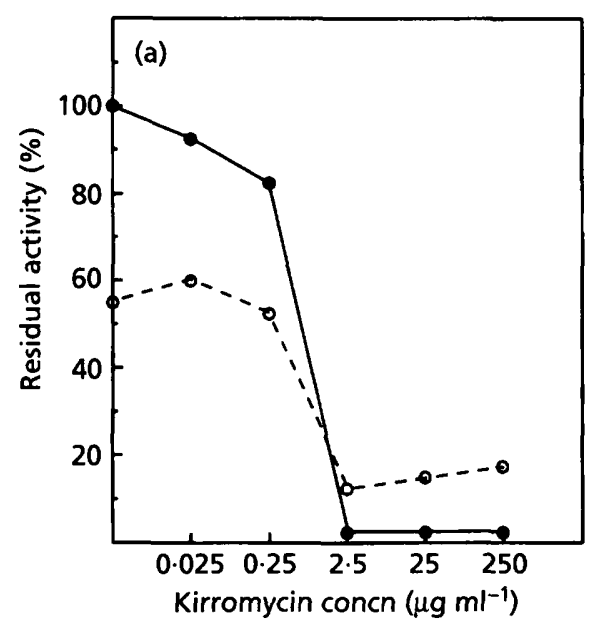

(b)

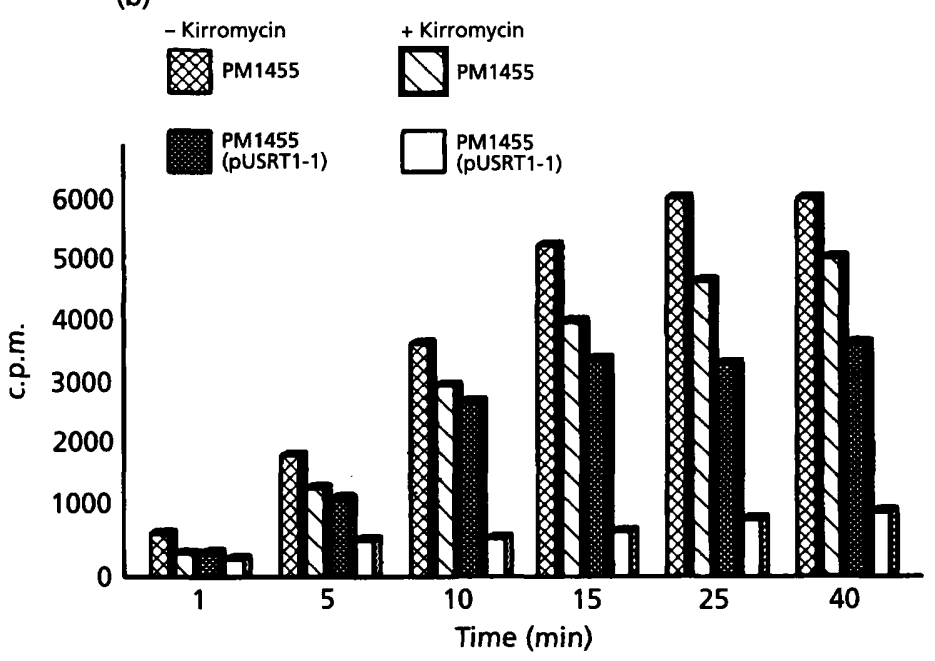

Fig. 8. EF-Tu1 is kirromycin sensitive. (a) Poly(U)-directed incorporation of $\left[{ }^{14} \mathrm{C}\right]$ phenylalanine into trichloroacetic acid precipitable material was studied as a function of the kirromycin concentration in an in vitro translation system dependent on EF-Tu. Reactions were carried out with ribosomes and EF-G isolated from E. coli. 0 . Incorporation of ${ }^{14} C$ label observed with Ec.EF-Tu (isolated from LBE1001, a wild-type E. coli strain) in the absence of kirromycin, normalized to $100 \%$. O. EF-Tu1, isolated from S. ramocissimus. For experimental details see van der Meide (1982). (b) Poly(U)directed poly(Phe) synthesis was measured with and without $30 \mu \mathrm{g}$ kirromycin $\mathrm{ml}^{-1}$ in $\mathrm{S} 30$ supernatants of the kirromycinresistant E. coli strain PM1455 and in PM1455 transformed with pUSRT1-1. The S30 supernatants were fractionated over Sephadex G-25 and the first four fractions with an absorbance at $260 \mathrm{~nm}$ were combined. An aliquot was incubated with tRNA, $\left[{ }^{3} \mathrm{H}\right]$ Phe and poly $(U)$ at $37^{\circ} \mathrm{C}$ (for experimental details see Luiten et al., 1991). Samples were taken at the indicated times and in vitro translation of poly $(U)$ was measured as trichloroacetic acid precipitable ${ }^{3} \mathrm{H}$-labelled product. 


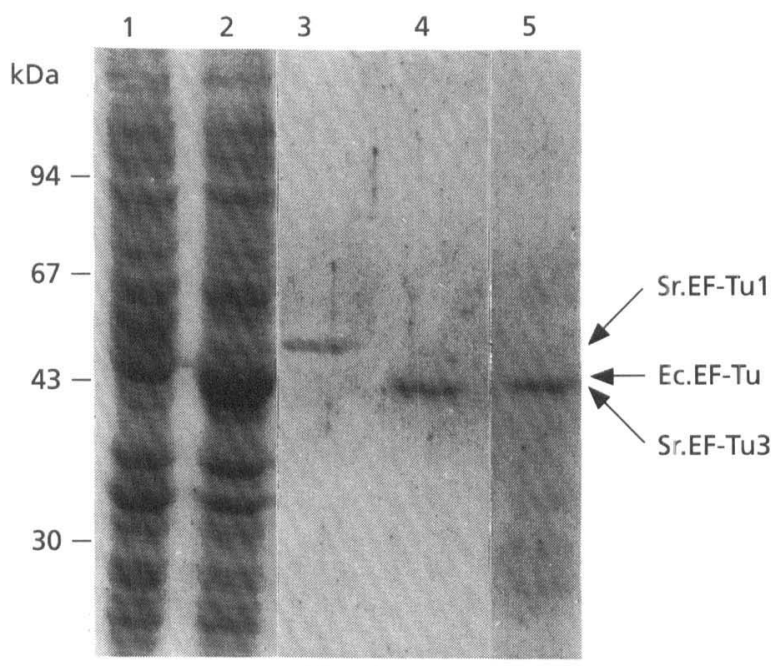

Fig. 9

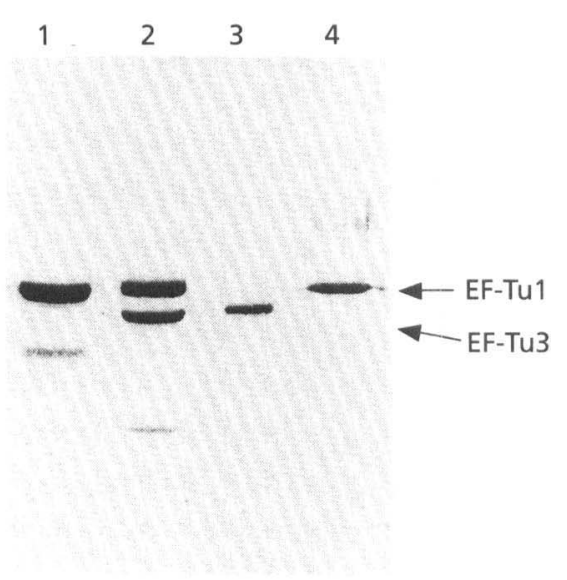

Fig. 10

Fig. 9. Expression of tuf-3 in E. coli studied with SDS-PAGE. Proteins were stained with Coomassie Brilliant Blue. Lane 1, total extract of KA797 cultured for $8 \mathrm{~h}$ in LB medium; lane 2, total extract of KA797(pUSRT3-3) cultured for $8 \mathrm{~h}$ in LB medium and induced with IPTG during the last $2 \mathrm{~h}$; lane 3, EF-Tu1 purified from S. ramocissimus; lane 4, purified EF-Tu3; lane 5, Ec.EF-Tu.

Fig. 10. Western blot analysis of EF-Tu1 and EF-TU3 probed with antibodies against Sr.EF-Tu3. Lane 1, Sc.EF-Tu1 - S30 supernatant fraction of liquid grown S. coelicolor M145; lane 2, Sc.EF-Tu1 and EF-TU3 - S30 supernatant fraction of liquid-grown S. coelicolor M145 pISRT3-1; lane 3, EF-Tu3 purified from E. coli JM101(pUSRT3-3); lane 4, EF-Tu1 isolated from S. ramocissimus.

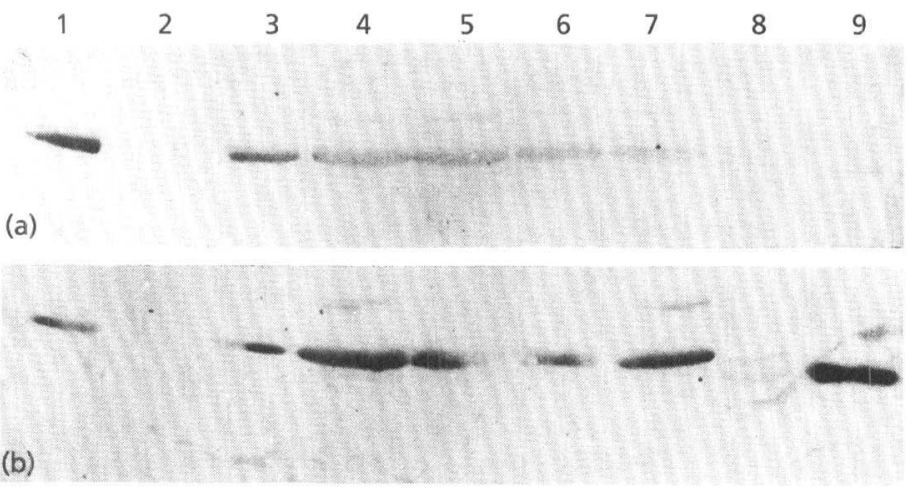

Fig. 11

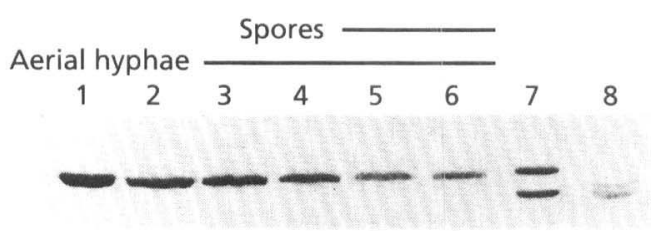

Fig. 12

Fig. 11. Temporal expression of tuf genes in submerged cultures of $S$. ramocissimus, studied with Western blotting using anti-EF-Tu1 (a) and anti-EF-Tu3 (b). Lane 1, purified EF-Tu1; lane 2, S30 pellet fraction after $20 \mathrm{~h}$ culturing; lane 3, S30 supernatant fraction after $20 \mathrm{~h}$ culturing; lane 4, S30 pellet fraction after $44 \mathrm{~h}$; lane 5, S30 supernatant fraction after $44 \mathrm{~h}$; lane 6, S30 pellet fraction after $68 \mathrm{~h}$; lane 7, S30 supernatant fraction after $68 \mathrm{~h}$; lane 8, EF-Tu2 and Ec.EF-Tu, total extract of $E$. coli JM101(pUSRT2-3); lane 9, EF-TU3 purified from E. coli JM101(pUSRT3-3).

Fig. 12. Western blot of extracts from surface-grown S. ramocissimus. The blot was incubated with antibodies raised against the tuf-3 product. In lanes 1 to 6 equal amounts of protein were loaded. $S$. ramocissimus was grown on minimal medium. The bars above the Western blot indicate the presence of aerial hyphae $(42-80 \mathrm{~h})$ and of spores $(58-80 \mathrm{~h})$ as observed by phase-contrast microscopy. $\$ 30$ supernatant fractions were prepared after $18 \mathrm{~h}$ (lane 1), $27 \mathrm{~h}$ (lane 2), $42 \mathrm{~h}$ (lane 3), $51 \mathrm{~h}$ (lane 4), $66 \mathrm{~h}$ (lane 5), and $80 \mathrm{~h}$ (lane 6) of growth. Lane 7, Sc.EF-Tu1 and EF-Tu3 - S30 supernatant of liquidgrown S. coelicolor M145(pISRT3-1); lane 8, EF-Tu2 and EC.EF-Tu - S30 supernatant of E. coli JM101(pUSRT2-3).

product. The Western blot of Fig. 10 revealed the presence of both EF-Tu3 and S. coelicolor EF-Tu1 (Sc.EF-Tu1) in the transformed cells (Fig. 10, lane 2) and that of solely
Sc.EF-Tu1 in the parental cells (Fig. 10, lane 1). This demonstrated that Sc.EF-Tu1 is recognized by the antibodies raised against the $t u f-3$ product and that it has 
the same migration rate as EF-Tu1 of S. ramocissimus (Fig. 10, lanes 1,2 and 4). EF-Tu3 obtained from pISRT3-1 expression in $S$. coelicolor migrated at the same rate as does the product of heterologously expressed $t u f-3$. Therefore we suppose that EF-Tu3, when synthesized in S. ramocissimus, behaves similarly during SDS-PAGE. Overexpression of tuf-2 in S. coelicolor has not yet been achieved. But assuming that EF-Tu2 is recognized by both types of antibodies and that it migrates as demonstrated for the product of tuf-2 expressed in E. coli, EF-Tu2 can be detected as well.

\section{Temporal tuf gene expression in S. ramocissimus}

Submerged mycelium of $S$. ramocissimus was cultured for various periods of time in $\mathrm{S}$ medium, whereafter the mycelium was sonicated and the resulting suspensions were centrifuged at $30000 \mathrm{~g}$. Under these culture conditions kirromycin is produced. This was demonstrated by extraction of the antibiotic from the medium and analysis with thin-layer chromatography (data not shown). S30 pellets and S30 supernatants were then submitted to SDS-PAGE and immunoblotting using anti-EF-Tu1 (Fig. 11a) and anti-EF-Tu3 (Fig. 11b). EFTu1 is clearly present in S30 supernatants (but not in S30 pellets) of exponentially growing cells $(20 \mathrm{~h}$ cultures, lanes 2 and 3). Larger amounts can be seen, both in the pellet and in the supernatant fractions of cells cultured for $44 \mathrm{~h}$ (lanes 4 and 5) and $68 \mathrm{~h}$ (lanes 6 and 7). A very faint band is visible at the position of EF-Tu2 but its appearance was not reproducible and degradation of EF-Tu1 cannot be excluded. A signal corresponding to EF-Tu3 was not observed.

Surface-grown cultures of Streptomyces show complete morphological differentiation. It was of interest to investigate whether or not expression of tuf genes coincides with one or more of the differentiation stages. Surfacegrown cells from $S$. ramocissimus were therefore cultured on minimal medium for various periods of time. S30 supernatant fractions, analysed by Western blotting using anti-EF-Tu3 (Fig. 12, lanes 1-6), showed the presence of EF-Tu1 only. A similar analysis of S30 supernatant fractions from pre-germinated spores and aerial hyphae also revealed the presence solely of EF-Tu1 (not shown).

\section{DISCUSSION}

The presence of three tuf-like genes in the mycelial bacterium $S$. ramocissimus is intriguing. As outlined in the Introduction, the group of Gram-positive bacteria was assumed to harbour only one tuf gene. Our results indicate that this is not so in the case of $S$. ramocissimus and most likely not in that of more, if not all, Streptomyces spp. (Fig. 4). The location of $t u f-1$, i.e. downstream of $f u s$, is similar to that of E. coli tuf $A$ in the stroperon and is in line with tuf-1 encoding a genuine EF-Tu. This is confirmed by the characterization of the tuf- 1 product in vitro (Fig. 8). Evidence for a gene organization like that of the E. coli tufB operon (four tRNA genes preceding $t u f B$ ) was not obtained for either $t u f-2$ or $t u f-3$.
A further striking finding is that the amino acid sequences of EF-Tu1, 2 and 3 from $S$. ramocissimus are not as similar as those of EF-TuA and B from E. coli. In the fungus Rhizomucor racemosus, the products of the three genes coding for EF- $1 \alpha$ show $99 \%$ identity. On the other hand, the eukaryote Xenopus laevis has three genes encoding EF$1 \alpha$ which do not show the strong sequence conservation of their products as observed in other organisms (Djé et al., 1990). Two EF-1 $\alpha$ genes, one expressed in embryos and adult cells $(\mathrm{EF}-1 \alpha \mathrm{S})$, the other in oocytes $(\mathrm{EF}-1 \alpha \mathrm{O})$, have a high product identity $(91 \%)$. The EF-1 $\alpha(42 \mathrm{Sp} 50)$ encoded by the third gene has an identity of only $69 \%$ compared to the other two (Deschamps et al., 1991). It is found in so-called storage particles as a complex with 5S RNA and various tRNAs (Djé et al., 1990, and references therein). The possibility may be envisaged, therefore, that EF-Tu3 from $S$. ramocissimus has a specialized function. In this context, it is worth mentioning that the identity between EF-Tu1 and EF-Tu2 is $88 \%$, whereas that between EF-Tu3 and the other EF-Tus from the streptomycete is only $65 \%$.

The sequence data do not provide any indication that one of the streptomycete EF-Tus might be kirromycin resistant. Amino acid residues (indicated in bold type in Fig. 3 ) known to be altered in kirromycin-resistant E. coli EFTu mutants, i.e. residues 375, 316, 222, 124 (Duisterwinkel et al., 1984; Zeef \& Bosch, 1993) and 329 (Abdulkarim $e t$ al., 1991) are conserved in all three $S$. ramocissimus EFTus. Kirromycin resistance due to residues elsewhere in the molecule cannot be excluded. We, therefore, expressed the three tuf-like genes in E. coli and studied their temporal expression in $S$. ramocissimus. After heterologous expression of tuf -1 most of the product can be recovered from $E$. coli in a soluble form. By contrast, heterologous expression of tuf-2 and tuf-3 yields inactive products, deposited in inclusion bodies. We do not know what determines the different fate of the three tuf products. Incorrect folding of the nascent chain has been invoked to explain this phenomenon, observed after over-expression of foreign genes. If so, it is unclear why the products of tuf-2 and tuf-3 should not fold properly during de novo synthesis in E. coli, whereas the tuf- 1 product folds correctly. Functional differences between the gene products may be considered in this context.

Although functional characterization of only the tuf-1 gene product has been achieved, heterologous gene expression of all three genes in $E$. coli enabled the identification of each protein and the production of antibodies. A larger difference in molecular mass was observed in the Western blots than expected on the basis of the amino acid sequence derived from the nucleotide sequence (maximally eight amino acid residues). Posttranslational modification seems an unlikely explanation since both the tuf- 1 and tuf- 3 products, either homologously or heterologously expressed, displayed the same electrophoretic migration rate.

One of the questions of interest is whether kirromycin production coincides with the expression of one or more of the tuf genes. It has been shown in E. coli that kirromycin sensitivity is dominant over kirromycin re- 
sistance (van de Klundert et al., 1978). Provided that this rule applies to $S$. ramocissimus and that either tuf- 2 or tuf3 encodes a kirromycin-resistant EF-Tu, we would expect a clear reduction of the amount of EF-Tu1, which is kirromycin sensitive, and a simultaneous increase in concentration of EF-Tu2 or EF-Tu3. We could only identify unambiguously one tuf product, EF-Tu1, in submerged cultures of $S$. ramocissimus under conditions when kirromycin is produced. Surface-grown cultures also produced EF-Tu1 only. If present in S. ramocissimus, the intracellular amount of EF-Tu2 and EF-Tu3 is less than a few percent of that of EF-Tu1. These data suggest that protection of $S$. ramocissimus against its own product, kirromycin, is not provided by alteration of EF-Tu. Protection must therefore be achieved by mechanisms such as efficient transport of the antibiotic out of the cell, deposition of it in an intracellular compartment or intracellular modification (for a review see Cundliffe, 1989).

The absence of detectable tuf- 2 and $t u f-3$ expression raises the question whether they are silent genes or expressed at very low levels. We opt for the latter and suggest that they have specialized functions not requiring the high concentration normally found for elongation factor $\mathrm{Tu}$. An obvious experimental approach to investigate whether tuf- 2 and/or $t u f-3$ are essential would be gene inactivation. Up till now we have been unable to transform $S$. ramocissimus. Other Streptomyces spp. such as $S$. coelicolor and S. lividans can be transformed readily (Hopwood et al., 1985). Therefore the perspective of studying tuf-3 inactivation in one of these strains is much more promising.

\section{ACKNOWLEDGEMENTS}

We thank Drs R. G. M. Luiten, J. A. van den Berg, R. F. Beudeker, B. Kraal and R. H. Cool for helpful discussions, and Drs P. H. van der Meide and P. van Solingen for some of the data presented in Fig. 8. This research was supported by Gistbrocades NV, The Netherlands and the Technology Foundation (STW) which is subsidized by the Netherlands Organization for Scientific Research (NWO).

\section{REFERENCES}

Abdulkarim, F., Tuohy, T. M. F., Buckingham, R. H. \& Hughes, D. (1991). Missense substitutions lethal to essential functions of EFTu. Biocbimie 73, 1457-1464.

An, G. \& Friesen, J. D. (1980). The nucleotide sequence of $t u f B$ and four nearby tRNA structural genes of E. coli. Gene 12, 33-39.

Auer, J., Spicker, G. \& Bock, A. (1990). Nucleotide sequence of the gene for elongation factor EF-1 $\alpha$ from the extreme thermophilic archaebacterium Thermococcus celer. Nucleic Acids Res 18, 3989.

Bachleitner, M., Ludwig, W., Stetter, K. O. \& Schleifer, K. H. (1989). Nucleotide sequence of the gene coding for the elongation factor Tu from the extremely thermophilic eubacterium Thermotoga maritima. FEMS Microbiol Lett 57, 115-120.

Buttarelli, F. R., Calogero, R. A., Tiboni, O., Gualerzi, C. O. \& Pon, C. L. (1989). Characterization of the str operon genes from Spirulina platensis and their evolutionary relationship to those of other prokaryotes. Mol \& Gen Genet 217, 97-104.

Chater, E. F. (1989). Multilevel regulation of Streptomyces differentiation. Trends Genet 5, 372-377.
Cundliffe, E. (1989). How antibiotic-producing organisms avoid suicide. Annu Rev Microbiol 43, 207-233.

Deschamps, S., Morales, J., Mazabraud, A., le Maire, M., Denis, H. \& Brown, D. D. (1991). Two forms of elongation factor 1 (EF-1 $\alpha \mathrm{O}$ and $42 \mathrm{Sp} 50$ ), present in oocytes, but absent in somatic cells of Xenopus laevis. J Cell Biol 114, 1109-1111.

Dever, T. E., Glynias, M. J. \& Merrick, W. C. (1987). GTP-binding domain: Three consensus sequence elements with distinct spacing. Proc Natl Acad Sci US A 84, 1814-1818.

Devereux, T., Haebarli, P. \& Smithies, O. (1984). A comprehensive set of sequence analysis programs for the VAX. Nucleic Acids Res $12,387-395$.

Djé, M. K., Mazabraud, A., Viel, A., le Maire, M., Denis, H., Crawford, E. \& Brown, D. D. (1990). Three genes under different developmental control encode elongation factor $1 \alpha$ in Xenopus laevis. Nucleic Acids Res 18, 3489-3493.

Duffy, L. K., Gerber, L., Johnson, A. E. \& Miller, D. L. (1981). Identification of a histidine residue near the aminoacyl transfer ribonucleic acid binding site of elongation factor Tu. Biochemistry 20, 4663-4666.

Duisterwinkel, F. J., Kraal, B., de Graaf, J. M., Talens, A., Bosch, L., Swart, G. W. M., Parmeggiani, A., La Cour, T. F. M., Nyborg, J. \& Clark, B. F. C. (1984). Specific alterations of the EF-Tu polypeptide chain considered in the light of its three-dimensional structure. EMBO J 3, 113-120.

Edwards, D. M. F., Selva, E., Stella, S., Zerilli, L. F. \& Gallo, G. G. (1992). Mass spectrometric techniques for structure and novelty determination of kirromycin-like antibiotics. Biol Mass Spectrom 21, 51-59.

Feinberg, A. P. \& Vogelstein, B. (1983). A technique for radiolabeling DNA restriction endonuclease fragments to high specific activity. Anal Biochem 132, 6-13.

Feinberg, A. P. \& Vogelstein, B. (1984). Addendum, Feinberg, A. P. and Vogelstein, B. (1983). Anal Biochem 137, 266-267.

Filer, D. \& Furano, A. V. (1981). Duplication of the tuf gene, which encodes peptide chain elongation factor $\mathrm{Tu}$, is widespread in Gram-negative bacteria. J Bacteriol 148, 1006-1011.

Forchhammer, K., Leinfelder, W. \& Bठck, A. (1989). Identification of a novel translation factor necessary for the incorporation of selenocysteine into protein. Nature 342, 453-456.

Frankel, S., Condeelis, J. \& Leinwand, L. (1990). Expression of Actin in Escherichia coli. J Biol Chem 265, 17980-17987.

Glockner, C. \& Wolf, H. (1984). Mechanism of natural resistance to kirromycin-type antibiotics in actinomycetes. FEMS Microbiol Lett 25, 121-124.

Goldstein, B. P., Zaffaroni, G., Tiboni, O., Amiri, B. \& Denaro, M. (1989). Determination of the number of tuf genes in Chlamydia trachomatis and Neisseria gonorrboeae. FEMS Microbiol Lett 60, 305-310.

Heinstra, P. W. H., Aben, W. J. M., Scharloo, W. \& Thörig, G. E. W. (1986). Alcohol dehydrogenase of Drosophila melanogaster: metabolic differences mediated through cryptic allozymes. Heredity 57, 23-29.

Hong, G. F. (1982). A systematic DNA sequencing strategy. $J \mathrm{Mol}$ Biol 158, 539-549.

Hopwood, D. A., Bibb, M. J., Chater, K. F., Kieser, T., Bruton, J., Kieser, H. M., Lydiate, D. J., Smith, C. P., Ward, J. M. \& Schrempf, H. (1985). Genetic Manipulation of Streptomyces. A Laboratory Manual. Norwich: JII.

Jacobson, G. R. \& Rosenbusch, J. P. (1977). Affinity purification of elongation factors Tu and Ts. FEBS Lett 79, 8-10.

Jaskunas, S. R., Lindahl, L., Nomura, M. \& Burgess, R. R. (1975). 
Identification of two copies of the gene for the elongation factor EF-Tu in E. coli. Nature 257, 458 462.

Kraus, M., Gotz, M. \& Loffelhardt, W. (1990). The cyanelle str operon from Cyanophora paradoxa: sequence analysis and phylogenetic implications. Plant Mol Biol 15, 561-573.

Kunkel, T. A. (1985). Rapid and efficient site-specific mutagenesis without phenotypic selection. Proc Natl Acad Sci US A 82, 488-492.

Laemmli, U. K. (1970). Cleavage of structural proteins during the assembly of the head of bacteriophage T4. Nature 227, 680-685.

Lechner, K. \& Böck, A. (1987). Cloning and nucleotide sequence of the gene for an archaebacterial protein synthesis elongation factor Tu. Mol \& Gen Genet 208, 523-528.

Lee, J. S., An, G., Friesen, D. \& Fiil, N. P. (1981). Location of the tufB promoter of Escherichia coli: cotranscription of tufB with four transfer ENA genes. Cell 25, 251-258.

Lindahl, L., Post, L., Zengel, J. M., Gilbert, S. F., Strycharz, W. A. \& Nomura, M. (1977). Mapping of ribosomal protein genes by in vitro protein synthesis using DNA fragments of .fus 3 transducing phage DNA as templates. $J$ Biol Chem 252, 7365-7383.

Loechel, S., Inamine, J. M. \& Hu, P. (1989). Nucleotide sequence of the tuf gene from Mycoplasma genitalium. Nucleic Acids Res 17, 10127.

Ludwig, W., Weizenegger, M., Betzl, D., Leidd, E., Lenz, T., Ludvigson, A., Möllenhoff, D., Wenzig, P. \& Schleifer, K. H. (1990). Complete nucleotide sequences of seven eubacterial genes coding for the elongation factor Tu: functional, structural and phylogenetic evaluations. Arch Microbiol 153, 241-247.

Luiten, R. G. M., Kerkman, R., Bosch, L., Vijgenboom, E., Heinstra, P. W. H. \& Woudt, L. P. (1991). Elfamycin-resistant mutants. European Patent Application EP 0466251 A1.

Maniatis, T., Fritsch, E. F. \& Sambrook, J. (1982). Molecular Cloning: A Laboratory Manual. Cold Spring Harbor, NY: Cold Spring Harbor Laboratory.

Meng, B. Y., Shinozaki, K. \& Sugiura, M. (1989). Genes for the ribosomal proteins $\mathrm{S} 12$ and $\mathrm{S} 7$ and elongation factors EF-G and EF-Tu of the cyanobacterium, Anacystis nidulans: structural homology between 16S rRNA and S7 mRNA. Mol \& Gen Genet 216, 25-30.

Messing, J. (1979). A multi-purpose cloning system based on the single-stranded DNA bacteriophage M13. Recomb DNA Tech Bull 2, 43-48.

Mickel, F. S. \& Spremuli, L. L. (1986). Organization of the genes for protein synthesis elongation factors $\mathrm{Tu}$ and $\mathrm{G}$ in the cyanobacterium Anacystis nidulans. J Bacteriol 166, 78-82.

Ohama, T., Yamao, F., Muto, A. \& Osawa, S. (1987). Organization and codon usage of the streptomycin operon in Micrococcus luteus, a bacterium with a high genomic $G+C$ content. J Bacteriol 169, 4770-4777.

Parmeggiani, A. \& Swart, G. W. M. (1985). Mechanism of action of kirromycin-like antibiotics. Annu Rev Microbiol 39, 557-577.

Parra, F., Blanco, G., Martin, J. M. A., Balbin, M., Mendez, C. \& Salas, J. A. (1992). Cloning and sequence of a gene encoding the L7/L12 ribosomal protein equivalent of Streptomyces antibioticus. Gene 118, 127-129.

Post, L. E. \& Nomura, M. (1980). DNA sequences from the str operon of Escherichia coli. J Biol Chem 255, 4660-4666.

Sanger, F., Nicklen, S. \& Coulsen, A. R. (1977). DNA sequencing with chain-terminating inhibitors. Proc Natl Acad Sci USA 74, 5463-5467.

Saraste, M., Sibbald, P. R. \& Wittinghofer, A. (1990). The P-loop, a common motif in ATP- and GTP-binding proteins. Trends Biocbem Sci 15, 430-434.

Satoh, M., Tanaka, T., Kushiro, A., Hakoshima, T. \& Tomita, K. (1991). Molecular cloning, nucleotide sequence and expression of the tufB gene encoding elongation factor $T u$ from Thermus thermophilus HB8. FEBS Lett 288, 98-100.

Seidler, L., Peter, M., Meissner, F. \& Sprinzl, M. (1987). Sequences and identification of the nucleotide binding site for the elongation factor Tu from Thermus thermophilus HB8. Nucleic Acids Res 15, 9263-9277.

Sela, S., Yogev, D., Razin, S. \& Bercovier, H. (1989). Duplication of the tuf gene: a new insight into the phylogeny of eubacteria. $J$ Bacteriol 171, 581-584.

Strohl, W. R. (1992). Compilation and analysis of DNA sequences associated with apparent streptomycete promoters. Nucleic Acids Res 20, 961-974.

Sundstrom, U., Lira, L. M., Choi, D., Linz, J. E. \& Sypherd, P. S. (1987). Sequence analysis of the EF-1 $\alpha$ gene family of Mucor racemosus. Nucleic Acids Res 15, 9997-10005.

Twigg, A. J. \& Sherratt, D. (1980). Trans-complementable copy number mutants of plasmid ColE1. Nature 283, 216-218.

van de Klundert, J. A. M., van der Meide, P. H., van de Putte, P. \& Bosch, L. (1978). Mutants of Eschericbia coli altered in both genes coding for the elongation factor Tu. Proc Natl Acad Sci US A 75, 4470-4473.

van der Meide, P. H. (1982). Mutants of Escherichia coli altered in tuf $A$ and tuf $\mathrm{B}$. PhD thesis. Leiden University, The Netherlands.

van der Meide, P. H., Borman, T. H., van Kimmenade, A. M. A., van de Putte, P. \& Bosch, L. (1980). Elongation factor Tu isolated from Escherichia coli mutants altered in tuf $A$ and $t u f B$. Proc Natl Acad Sci US A 77, 3922-3926.

van der Meide, P. H., Vijgenboom, E., Talens, A. \& Bosch, L. (1983a). The role of EF-Tu in the expression of tuf $A$ and $t u f B$ genes. Eur J Biocbem 130, 397-407.

van der Meide, P. H., Kastelein, R. A., Vijgenboom, E. \& Bosch, L. (1983b). tuf gene dosage effects on the intracellular concentration of EF-TuB. Eur J Biochem 130, 409-417.

van Noort, J. M., Kraal, B., Bosch, L., La Cour, T. F. M., Nyborg, J. \& Clark, B. F. C. (1984). Cross-linking of tRNA at two different sites of the elongation factor Tu. Proc Natl Acad Sci US A 81, 3969-3972.

van Noort, J. M., Kraal, B., Sinjorgo, K. M. C., Persoon, N. L. M., Johanns, E. S. D. \& Bosch, L. (1986). Methylation in vivo of elongation factor EF-Tu at lysine-56 decreases the rate of tRNAdependent GTP hydrolysis. Eur J Biochem 160, 551-561.

van Wezel, G. P., Vijgenboom, E. \& Bosch, L. (1991). A comparative study of the ribosomal RNA operons of Streptomyces coelicolor A3(2) and sequence analysis of $\operatorname{rrnA}$. Nucleic Acids Res 19, 4399-4403.

Vieira, J. \& Messing, J. (1982). The pUC plasmids, an M13mp7derived system for insertion mutagenesis and sequencing with synthetic universal primers. Gene 19, 259-268.

Wolf, H., Chinali, G. \& Parmeggiani, A. (1974). Kirromycin, an inhibitor of protein biosynthesis that acts on elongation factor $\mathrm{Tu}$. Proc Natl Acad Sci US A 71, 4910-4914.

Wright, F. \& Bibb, M. J. (1992). Codon usage in the $G+C$ rich Streptomyces genome. Gene 113, 55-65.

Woese, C. R. (1987). Bacterial evolution. Microbiol Rev 51, 221-271. Yanisch-Perron, C., Vieira, J. \& Messing, J. (1985). Improved M13 phage cloning vectors and host strains: nucleotide sequences of the M13mp18 and pUC19 vectors. Gene 33, 103-119.

Yokota, T., Sugisaki, H., Takanami, M. \& Kaziro, Y. (1980). The 
nucleotide sequence of the cloned $\operatorname{tuf} A$ gene of Escherichia coli. Gene 12, 25-31.

Zeef, L. A. H. \& Bosch, L. (1993). A technique for targeted mutagenesis of the EF-Tu chromosomal gene by M13 mediated gene replacement. Mol \& Gen Genet 238, 252-260.

Zengel, J. M., Archer, R. H. \& Lindahl, L. (1984). The nucleotide sequence of the Eschericbia coli fus gene, coding for elongation factor G. Nucleic Acids Res 12, 2181-2192.

Received 8 September 1993; revised 17 October 1993; accepted 26 October 1993. 